\title{
Article
}

\section{Statistical Meta-Analysis of Risk Factors for Endometrial Cancer and Development of a Risk Prediction Model Using an Artificial Neural Network Algorithm}

\author{
Suzanna Hutt ${ }^{1,2,+}$, Denis Mihaies ${ }^{3,+}$, Emmanouil Karteris ${ }^{4}$, Agnieszka Michael ${ }^{1}$, Annette M. Payne ${ }^{3, * \text { (D) }}$ \\ and Jayanta Chatterjee $1,2,5$
}

1 Academic Department of Gynaecological Oncology, Royal Surrey NHS Foundation Trust Hospital, Guildford GU2 7XX, UK; s.hutt@surrey.ac.uk (S.H.); a.michael@surrey.ac.uk (A.M.); jayanta.chatterjee1@nhs.net (J.C.)

2 Department of Clinical and Experimental Medicine, Faculty of Health and Medical Sciences, School of Biosciences and Medicine, University of Surrey, Guildford GU2 7XH, UK

3 Department of Computer Science, College of Engineering, Design and Physical Sciences, Brunel University, London UB8 3PN, UK; denismihaies@yahoo.com

4 Department of Life Sciences, Division of Biosciences, College of Health, Medicine and Life Sciences, Brunel University, London UB8 3PN, UK; emmanouil.karteris@brunel.ac.uk

5 Department of Cancer and Surgery, Imperial College London, London SW7 2BX, UK

* Correspondence: annette.payne@brunel.ac.uk

+ These authors contributed equally to this work.

check for updates

Citation: Hutt, S.; Mihaies, D.; Karteris, E.; Michael, A.; Payne, A.M.; Chatterjee, J. Statistical Meta-Analysis of Risk Factors for Endometrial Cancer and Development of a Risk Prediction Model Using an Artificial Neural Network Algorithm. Cancers 2021, 13, 3689. https://doi.org/ 10.3390/cancers13153689

Academic Editor: Stephen T. C. Wong

Received: 27 May 2021

Accepted: 9 July 2021

Published: 22 July 2021

Publisher's Note: MDPI stays neutral with regard to jurisdictional claims in published maps and institutional affiliations.

Copyright: (c) 2021 by the authors. Licensee MDPI, Basel, Switzerland. This article is an open access article distributed under the terms and conditions of the Creative Commons Attribution (CC BY) license (https:// creativecommons.org/licenses/by/ $4.0 /)$.
Simple Summary: A robust and comprehensive meta-analysis, for the first time, identified definitely that BMI is by far the most influential risk factor in endometrial cancer. Risk factors were previously only studied individually and or in smaller meta-analysis studies which grouped some factors together. BMI was shown to be an important risk factor with other factors less so, but no rank order was established. This work also offers, for the first time, a neural network computer model to predict the overall increase or decreased risk of cancer for individual patients, which is $98.6 \%$ accurate. This prediction can be used as a tool to determine if a patient should be considered for testing and to predict diagnosis, as well as to suggest prevention measures to patients.

Abstract: Objectives: In this study we wished to determine the rank order of risk factors for endometrial cancer and calculate a pooled risk and percentage risk for each factor using a statistical meta-analysis approach. The next step was to design a neural network computer model to predict the overall increase or decreased risk of cancer for individual patients. This would help to determine whether this prediction could be used as a tool to decide if a patient should be considered for testing and to predict diagnosis, as well as to suggest prevention measures to patients. Design: A meta-analysis of existing data was carried out to calculate relative risk, followed by design and implementation of a risk prediction computational model based on a neural network algorithm. Setting: Meta-analysis data were collated from various settings from around the world. Primary data to test the model were collected from a hospital clinic setting. Participants: Data from 40 patients notes currently suspected of having endometrial cancer and undergoing investigations and treatment were collected to test the software with their cancer diagnosis not revealed to the software developers. Main outcome measures: The forest plots allowed an overall relative risk and percentage risk to be calculated from all the risk data gathered from the studies. A neural network computational model to determine percentage risk for individual patients was developed, implemented, and evaluated. Results: The results show that the greatest percentage increased risk was due to BMI being above 25, with the risk increasing as BMI increases. A BMI of 25 or over gave an increased risk of $2.01 \%$, a BMI of 30 or over gave an increase of $5.24 \%$, and a BMI of 40 or over led to an increase of $6.9 \%$. PCOS was the second highest increased risk at $4.2 \%$. Diabetes, which is incidentally also linked to an increased BMI, gave a significant increased risk along with null parity and noncontinuous HRT of $1.54 \%, 1.2 \%$, and $0.56 \%$ respectively. Decreased risk due to contraception was greatest with IUD (intrauterine device) and IUPD (intrauterine progesterone device) at $-1.34 \%$ compared to $-0.9 \%$ with oral. Continuous 
HRT at $-0.75 \%$ and parity at $-0.9 \%$ also decreased the risk. Using open-source patient data to test our computational model to determine risk, our results showed that the model is $98.6 \%$ accurate with an algorithm sensitivity $75 \%$ on average. Conclusions: In this study, we successfully determined the rank order of risk factors for endometrial cancer and calculated a pooled risk and risk percentage for each factor using a statistical meta-analysis approach. Then, using a computer neural network model system, we were able to model the overall increase or decreased risk of cancer and predict the cancer diagnosis for particular patients to an accuracy of over $98 \%$. The neural network model developed in this study was shown to be a potentially useful tool in determining the percentage risk and predicting the possibility of a given patient developing endometrial cancer. As such, it could be a useful tool for clinicians to use in conjunction with other biomarkers in determining which patients warrant further preventative interventions to avert progressing to endometrial cancer. This result would allow for a reduction in the number of unnecessary invasive tests on patients. The model may also be used to suggest interventions to decrease the risk for a particular patient. The sensitivity of the model limits it at this stage due to the small percentage of positive cases in the datasets; however, since this model utilizes a neural network machine learning algorithm, it can be further improved by providing the system with more and larger datasets to allow further refinement of the neural network.

Keywords: endometrial cancer; risk; neural network

\section{Introduction}

Endometrial cancer is the fourth most common cancer among postmenopausal women in the United Kingdom with more than 9377 cases between 2015 and 2017 [1]. It is the most common gynecological cancer in developed countries, and it is commonly considered a "curable cancer" as approximately $75 \%$ of cases are diagnosed before the disease has spread outside the uterus [2]. It is known to be hormone-related, and many of the risk factors are linked to excessive levels of estrogen. With that said, statistics show that $34 \%$ of cases are preventable, as a large percentage of the population is unaware of the factors which raise the risk of developing this type of cancer.

The aim of this study was to determine the level of risk of six of the most commonly identified risk factors using a meta-analysis approach and then use these data to implement an algorithm within a risk prediction neural network model which uses machine learning to calculate an individual's risk. We wish to assist clinicians to better identify patients at risk of developing endometrial cancer and help patients make an informed choice about possible actions they can take to lessen their risk. Individualized options for decreasing a patient's risk on the basis of their risk factor data can be suggested to the patient in order to reduce the risk as much as possible. There are multiple expected benefits of a good prediction model, including the discovery of patients who are at a higher risk than normal and may benefit from targeted prevention treatment, the increasing awareness in patients about the risk factors which put them at a high risk, and the help provided to the clinicians in decision making.

Endometrial cancer statistics show that it is primarily a disease of postmenopausal women, with about $25 \%$ of cases occurring in premenopausal women, and $5 \%$ occurring in women younger than 40 years of age [3]. This type of cancer is known to be hormone-related and driven by estrogen; thus, the levels of estrogen and progesterone in a woman's body can affect her risk of endometrial cancer. Many of the risk factors are directly or indirectly linked to a state of excessive estrogen. During menopause, the levels of estrogen and progesterone shift, with a decrease in progesterone production. When estrogen hormone is present with subnormal levels of progesterone, it can cause the endometrium to become thickened, potentially leading to endometrial cancer [3]. Consequently, protective factors seem to be related to conditions that may result in decreased estrogen exposure. As the most common tumor of the female reproductive tract, endometrial cancer remains the fourth most common cancer in women in the developed world [1], with the incidence 
of endometrial cancer increasing rapidly concurrently with the increasing prevalence of obesity.

Breast, endometrial, and ovarian cancers share some hormonal and epidemiologic risk factors. There are several validated models which predict absolute risk of breast cancer such as the Gail model; however, there are fewer models for ovarian cancer and endometrial cancer. One study proposed an actual risk prediction model for endometrial cancer, and, although the study presented some interesting points, the proposed model had several limitations [4]. One limitation is that the risk factors considered are given weights based on assumptions, rather than using pooled risk ratios of multiple studies which examine the relationship of the specific risk factors and endometrial cancer or the use of logistic regression. Additionally, the prevention techniques described are generic and are based on the risk category of the patient and not on the particular risk factors. A validated risk prediction model which is based on easily obtainable epidemiologic and clinical data which can accurately predict a person's risk is, therefore, urgently required. It can assist in identifying individuals at particularly high risk of developing endometrial cancer and who may benefit from targeted primary prevention strategies, as well as determine whether endometrial testing is needed or not.

Across Europe, it has been estimated that $60 \%$ of endometrial cancer cases may be due to excess body weight. Worldwide, the prevalence of obesity (body mass index, BMI $>30 \mathrm{~kg} / \mathrm{m}^{2}$ ) has doubled in the last three decades; each year, 2.8 million people around the world die as a result of being overweight or obese. Among women, obesity is more strongly associated with the development of endometrial cancer than any other cancer type [5] and, similarly to Europe, approximately $57 \%$ of endometrial cancers in the United States are thought to be attributable to being overweight and obese [6]. This is not necessarily something surprising, as endometrial cancer is hormone-related and obesity is also closely tied to hormonal changes, including estrogen levels, considering that obese or overweight women have higher rates of circulating estrogen in their bloodstream. Despite the clear evidence of obesity associated with endometrial cancer, there is still limited public awareness of the relationship as healthcare providers are often reluctant to counsel patients with endometrial cancer about obesity.

Smoking is a great risk factor for any type of cancer, although studies show that smoking does not obviously correlate with endometrial cancer, with some studies even suggest that smoking is a protective risk factor [7]; this risk factor was, therefore, not included in this risk model.

Reproductive factors are also strongly tied to hormonal changes and were considered; this includes parity and the use of contraceptive methods. It has been demonstrated that a woman who has given at least one birth during her lifetime has a lower risk of developing endometrial cancer, as the hormonal balance shifts toward more progesterone during pregnancy [8]. On the other hand, women who have never been pregnant have a higher risk, especially if they are also infertile. For the same reason, use of the combined oral contraceptive pill (COCP) or intrauterine progesterone device (IUPD/IUS) is associated with a significant reduction in endometrial cancer risk due to suppression of endogenous estrogen levels and increased exposure to progesterone throughout the menstrual cycle [9]. Some studies have shown that polycystic ovary syndrome, which affects $6-8 \%$ of women of reproductive age, and insulin insensitivity (or resistance), which are both components of metabolic syndrome, may play a role in the pathogenesis of endometrial cancer, perhaps through hormonal disruption, which causes higher androgen and estrogen levels and lower progesterone levels [10].

Hyperinsulinemia and the insulin-resistant state are known to be associated closely with obesity. The positive association of endometrial cancer with hyperinsulinemia and type 2 diabetes is well documented, and several studies have shown an association of type 2 diabetes with endometrial cancer risk.

Hormone replacement therapy increases the levels of circulating estrogen, which is required to reduce vasomotor symptoms such as hot flushes and night sweats. This therapy 
may reduce postmenopausal symptoms and prevent long-term problems due to estrogen deficiency. Sequential HRT is known to increase the risk of endometrial cancer, with risk being inversely proportional to the number of days progestin is given for. Continuous combination HRT, on the other hand, has been shown not to increase endometrial cancer risk and may even reduce it, presumably because of the protective effects of progesterone on the endometrium [11]. However, endometrial cancer is a hormone-sensitive carcinoma, and the use of HRT may stimulate estrogen receptors in residual carcinoma cells. These risk factors have been strongly associated with endometrial cancer, and clear evidence of the relationship between them and endometrial cancer has been shown.

\section{Preventive Measures According to Cancer Research UK}

Statistics from 2015 show that $34 \%$ of all cases of endometrial cancer are preventable [12]; therefore, the right prevention techniques are needed to help patients mitigate the risk of developing this type of cancer and eventually reduce this number where possible. Obesity is the most avoidable risk factor and is the leading risk factor for this and many cancer types [12]. Calorie-controlled diets, regular physical exercise in life, and adopting a Mediterranean diet [13] have been shown to help reduce the risk of endometrial cancer by losing excess weight. For morbidly obese patients, bariatric surgery may be the best option as it produces significant and durable results [14]. These lifestyle modifications also help to ameliorate polycystic ovary syndrome, which is another risk factor of endometrial cancer. Medications such as metformin which have been shown to help prevent and treat type 2 diabetes and PCOS also lower the risk in women who are prone to endometrial cancer $[15,16]$. However, as diabetes and PCOS are strongly associated with obesity, it is important that the patient reduces their BMI significantly to lower their overall risk, in addition to taking medications.

Given the growing importance of predictive medicine, there is a growing reliance on machine learning to make diagnostic predictions. Most studies using machine learning in the medical arena targeted breast cancer and were concerned with three clinical endpoints: (1) the prediction of cancer susceptibility, (2) the prediction of cancer recurrence, and (3) the prediction of cancer survivability [17]. Recently, machine learning algorithms, which used a set of clinical features including risk factors as input, were used to make predictions on breast cancer patients [18]. The algorithms showing the best accuracy in these studies were the artificial neural network and the K-nearest neighbor algorithms, with almost all reported studies concerning cancer prediction using an artificial neural network as their primary predictor, as it has the ability to learn and model nonlinear and complex relationships [17]. Furthermore, these studies showed that the use of artificial neural networks could substantially improve the accuracy of cancer susceptibility and cancer outcome prediction relative to simple statistical methods.

In this study, we wished to determine the rank order of risk factors for endometrial cancer and calculate a pooled risk and percentage risk for each factor using a statistical meta-analysis approach. Then, a neural network computer model was designed to predict the overall increase or decreased risk of cancer for particular patients. This prediction can be used as a tool to determine if a patient should be considered for screening testing and to predict diagnosis, as well as to suggest prevention measures to patients.

\section{Methods}

\subsection{Meta-Analysis and Determination of Pooled Risk}

A meta-analysis of data from articles that studied the relationship of endometrial cancer and six chosen risk factors (obesity, contraception use, hormone-replacement therapy (HRT), type 2 diabetes, polycystic ovary syndrome (PCOS), and parity) was conducted. The total number of articles identified from a literature search using these key words prescreening was 9463. Articles were then screened and selected according to strict criteria, and the data therein were categorized as follows: 


\begin{tabular}{cc}
\hline Inclusion Criteria & Exclusion Criteria \\
\hline & Other cancers \\
& Lynch syndrome \\
Endometrial cancer & Other genetics/gene mutations \\
Risk factors & Mortality risks \\
Women & Nonhuman \\
Publication dates 2003-2019 & $<2003$ \\
English language & Non-English \\
& Reviews without data \\
& Case reports \\
& Letters, news, notes, commentaries, and editorials \\
& Conference abstracts \\
& Book chapters \\
& Family history \\
\hline
\end{tabular}

On further reviewing papers, those that reported on particular risk factors considered identifiable/modifiable within primary care without need for investigation (listed below) were chosen for a second screen.

Risk factors within primary care included the following:

- Obesity-BMI/anthropometry,

- Diabetes-including IGT (impaired glucose tolerance),

- Parity,

- PCOS,

- HRT,

- Contraceptives.

A total of 111 articles were then put through a second screen to be included in the meta-analysis. Articles were excluded in this second screen on the basis of the following:

- Not enough published data to perform analysis,

- No/poor controls in study design,

- Numbers too small $(<15)$,

- Old datasets-not relevant to current clinical management,

- Heterogeneous data,

- Combined risk factor data only (unable to analyze risk factors individually).

A total of 51 articles were included in the meta-analysis with data obtained from non-randomized controlled studies (e.g., case-control, case-cohort), investigating the relationship of one or more of the risk factors above and endometrial cancer, where other factors were controlled for. Data were expressed as risk estimates such as odds ratio (OR), risk ratio (RR), hazard ratio (HR), and standard incidence ratio (SIR) with $95 \%$ confidence intervals (CIs).

Of the 51 studies that met the inclusion criteria, nine studies were related to contraceptive use (four oral and five IUD/IUPD), six studies were related to HRT (six continuous use and six noncontinuous), seven studies were related to parity (five for nulliparity and two for parity), 14 studies related to type 2 diabetes, two studies were related to polycystic syndrome (PCOS), and 18 studies were related to obesity (six for a BMI over 25, 16 for BMI over 30, and two for BMI over 40). Some studies collected data on multiple risk factors and, thus, were used in more than one calculation.

Regarding obesity, only articles that measured the body mass index (BMI) rather than other measurements of body weight were used since this is a well-established and objective measurement. According to the World Health Organization, a person is considered overweight when their BMI is over 25, obese when their BMI is over 30, and morbidly obese when is over 40 [19]. These three categories were used to subdivide data from the articles as each of them presents a different relative risk, the risk increasing with an increase in BMI. 
Contraception use was divided into two categories, the use of either oral contraceptives or intrauterine progesterone device (IUPD), being the most widely used methods of contraception throughout the world, which have been shown to have a relationship with endometrial cancer risk [14,20].

Hormone-replacement therapy was divided into two categories (continuous level or cyclical level), including those who had or are currently receiving this treatment, as each therapy type is known to have a different risk of endometrial cancer incidence [19,21].

Parity was divided into two categories (nulliparous women and women who have given birth at least once). Multiple studies have shown that parity does affect the risk of endometrial cancer, and a slight decrease of risk was shown in women who have a parity of over two in comparison to women who gave birth just once [22,23]; however, this difference was not great enough to be taken into consideration.

The type 2 diabetes and polycystic ovary syndrome studies used included data from individuals who were divided into sufferers and non-sufferers.

The 51 studies used in the meta-analysis are given in the Table 1.

Table 1. Studies used in the meta-analysis of risk factors.

\begin{tabular}{|c|c|}
\hline Study Code Number & Reference \\
\hline Obesity 13 & Jenabi, E., Poorolajal, J. (2015) [24] \\
\hline Obesity 15 & Gao, Y. et al. (2016) [25] \\
\hline Obesity 17 & Zhang, Y. et al. (2014) [26] \\
\hline Obesity and anthropometry 3 & $\mathrm{Xu}$, W.H. et al. (2005) [27] \\
\hline Weight change 10 & Nagle, C.M. et al. (2013) [28] \\
\hline Weight gain 6 & Lu, L. et al. (2011) [29] \\
\hline Anthropometry 2 & Maso, L. et al. (2011) [30] \\
\hline Anthropometry 3 & Schouten LJ et al. (2004) [31] \\
\hline Obesity 1 & Reeves, G.K. et al. (2007) [5] \\
\hline Obesity 6 & Jonsson, F. et al. (2003) [32] \\
\hline Obesity 12 & Wise, M.R. et al. (2016) [33] \\
\hline Obesity 14 & Rota, M. et al. (2015) [34] \\
\hline Weight change 8 & Liu, Y. et al. (2016) [35] \\
\hline Weight change 9 & Horn-Ross, P.L. et al. (2016) [36] \\
\hline Diabetes 2 & Attner, B. et al. (2012) [37] \\
\hline Anthropometry 1 & Friedenreich, C. et al. (2007) [38] \\
\hline Population 6 & Yang, H.P. et al. (2012) [39] \\
\hline Obesity 4 & Lindemann, K. et al. (2009) [40] \\
\hline Diabetes 1 & Friberg, E. et al. (2007) [41] \\
\hline Diabetes 3 & Friberg, E. et al. (2007) [42] \\
\hline Diabetes 4 & Lindemann, K. et al. (2008) [43] \\
\hline Diabetes 5 & Bosetti, C. et al. (2012) [44] \\
\hline Diabetes treatment 1 & Luo, J. et al. (2014) [45] \\
\hline Prediabetes 1 & Huang, Y. et al. (2014) [46] \\
\hline Prediabetes and diabetes 1 & Lambe M et al. (2011) [47] \\
\hline Type 2 diabetes 1 & Johnson, J.A. et al. (2011) [48] \\
\hline Type 2 diabetes 2 & Lin, C.C. et al. (2014) [49] \\
\hline Type 2 diabetes 3 & Oberaigner, W. et al. (2014) [50] \\
\hline Type 2 diabetes 4 & Liu, X. et al. (2015) [51] \\
\hline Type 2 diabetes 5 & Lo, S.F. et al. (2013) [52] \\
\hline HRT 4 & Razavi, P. et al. (2010) [53] \\
\hline HRT 5 & Jaakkola, S. et al. (2011) [54] \\
\hline HRT 9 & Mørch, L.S. et al. (2016) [55] \\
\hline HRT 10 & Doherty, J.A. et al. (2007) [56] \\
\hline HRT 11 & Beral, V. et al. (2005) [19] \\
\hline HRT 13 & Trabert, B. et al. (2013) [57] \\
\hline COCP + IUD & Tao, M.H. et al. (2006) [58] \\
\hline IUD 1 & Felix, A.S. et al. (2015) [59] \\
\hline IUD 2 & Beining, R.M. et al. (2008) [60] \\
\hline
\end{tabular}


Table 1. Cont.

\begin{tabular}{cl}
\hline Study Code Number & \multicolumn{1}{c}{ Reference } \\
\hline MIRENA & Jareid, M. et al. (2018) [61] \\
Reproductive factors 1 & Wernli, K.J. et al. (2006) [62] \\
Reproductive factors 2 & Xu, W.H. et al. (2004) [63] \\
Parity 7 & Yang, H.P. et al. (2015) [64] \\
Timing of birth 2 & Pfeiffer, R.M. et al. (2009) [65] \\
COCP 1 & Cook, L.S. et al. (2014) [66] \\
COCP 2 & Hannaford, P.C. et al. (2007) [67] \\
COCP 4 & Collaborative Group on Epidemiological \\
Parity 5 & Studies on Endometrial Cancer. (2015) [68] \\
Reproductive factors 4 & Wu, Q.J. et al. (2015) [22] \\
PCOS 1 & Brinton, L.A. et al. (2007) [69] \\
PCOS 2 & Fearnley, E.J. et al. (2010) [70] \\
\hline
\end{tabular}

The risks of each factor were transformed into risk percentages to be implemented into the STATA software (https: / / www.stata.com/features/meta-analysis/, accessed on 24 April 2021), which was used to conduct all analyses. Forest plots were drawn to combine the risk results for each factor. The pooled risk ratios were then used to derive an absolute lifetime risk and to determine how much each risk factor contributes to the lifetime risk. According to Cancer Research UK and associated studies, the estimated lifetime risk for a female being diagnosed with endometrial cancer is about $2.8 \%$ [72], meaning that one in 36 women will develop this disease at some stage in their life. Based on that number and the results from the forest plots, we transformed the relative risk of each risk factor type into risk percentage. A relative risk that is higher than 1 means that the specific factor puts the patient at a higher risk, while a relative risk lower than 1 is considered to be protective factor. As an example, we take the risk factor contraception use with IUD for which the pooled relative risk is 0.52 (see IUD forest plot in Figure 7), meaning that it reduces the risk by 0.48 or $48 \%$; therefore, a person's lifetime risk of $2.8 \%$ is reduced by $48 \%$ to $1.35 \%$ if they have ever used an intrauterine device. On the other hand, a BMI $\geq 40$ has a relative risk of 3.47, which, using the same method, is translated to an increase of $6.9 \%$. Using this method, the relative risk for each risk factor was calculated.

\subsection{Design and Implementation of a Computational Risk Prediction Model}

The risk prediction model was based on a neural network algorithm. This is a classification algorithm that attempts to recognize underlying relationships in a dataset through a process that mimics the way the human brain operates. We wished to use the model to predict whether a patient with a specified set of characteristics had a high chance of developing endometrial cancer or not and, therefore, should be considered for testing, as well as to suggest any preventative measures that the patient could put in place to lessen their risk. For the creation of this model, we obtained the endometrial cancer patient dataset from the National Cancer Institute (NCI) (see Section 2.5).

The model produces two main outputs, the calculated percentage risk and the prediction of whether the individual has a high risk of having cancer or not based on this percentage. If the combination of these two is positive, the system suggests that the patient should proceed to more classical clinical investigations for endometrial cancer. We evaluated the two outputs of this risk prediction model individually to determine how well they perform and to identify possible improvements to the algorithm. After training and testing the model using known data, we evaluated the model on some blind data from 40 patients (see below) and recorded the outputs. Multiple statistical analyses were performed on the results to determine any relationship between the percentage risk and the prediction accuracy with the eventual clinical diagnosis, as well as the relationship of the percentage risk and any individual risk factor. 
The model was implemented with a webpage interface (HTML was used to create the structure of the web page, CSS was used to describe the presentation of the web page, and JavaScript was used to provide the functionality needed). Visual Studio Code was used as the chosen source code editor. A neural net function (below) was used for the six risk factors mentioned earlier to predict the diagnosis of the patient.

\subsection{Risk Factors RStudio Code}

$\mathrm{NN}=$ neuralnet(diagnosis $\sim$ agelevel + bmi + diabetes + contraception + hrt + parity, trainNN, hidden $=c(4,2)$, threshold $=0.001$, stepmax $=1 \times 10^{6}$, linear.output $=$ FALSE).

Two hidden layers with four neurons for the first and two neurons for the second hidden layer were determined to be optimal to avoid under- or overfitting. This was used to plot the neural network using the training set. The compute function was used to predict the outcomes using the test dataset, which computed the outputs of all neurons for specific arbitrary covariate vectors by the trained neural network.

\subsection{Neural Network RStudio Code}

temp_test $\leq$ subset(testNN, select $=\mathrm{c}$ ("agelevel", "bmi", "diabetes", "contraception", "hrt", "parity")) NN.results $\leq$ compute(NN, temp_test) results $\leq$ data.frame(actual = testNN\$diagnosis, prediction $=$ NN.results $\$$ net.result) roundedresults $\leq$ sapply(results, round, digits $=0$ ).

The results were rounded to the nearest integer. The predictions were compared to actual values using a confusion matrix in order to evaluate how well it performed on the test dataset.

The full code in $\mathrm{R}$ is available in Supplementary File S1.

\subsection{Datasets}

An endometrial cancer open-source dataset was obtained from the National Cancer Institute (NCI), which contained risk factor data from each patient. We randomly selected 1200 records from this set that had data for the factors we were interested in, maintaining the same $95 \%-5 \%$ ratio of negative to positive cancer diagnosis as the whole dataset, giving 1142 instances (95\%) with a negative diagnosis and 58 with a positive diagnosis (5\%). These 1200 records were then randomly divided into a training dataset and a test dataset (70\% records for training and $30 \%$ for testing), while still maintaining the $95 \%-5 \%$ ratio in each set.

Further data from 40 patient notes currently suspected of having endometrial cancer and undergoing investigations and treatment at Royal Surrey NHS Foundation Trust Hospital were collected to test the software. Their cancer diagnosis was not provided to the software developers.

The data from both sets was anonymized.

Ethical approval was obtained from both Royal Surrey NHS Foundation Trust Hospital and Brunel University to collect the data and conduct the study. Patients gave consent for their data to be used in this study but were not actively involved.

\section{Results}

The results of the meta-analysis of the data from studies of each risk factor type using STATA software are presented in forest plots (see Figures 1-11). The forest plot displays the risk factor type, study labels, the summary data, graphical representation of the individual and overall effect sizes and their confidence intervals CIs, the corresponding values of the effect sizes and CIs, and the percentages of total weight for each study. In the graph, each study corresponds to a square, centered at a point estimate of the effect size with a horizontal line (whiskers) extending on either side of the square. The horizontal line depicts the CI. The area of the square is proportional to the corresponding study weight. The overall effect size corresponds to the diamond centered at the estimate of the overall 
effect size. The width of the diamond corresponds to the width of the overall CI. Note that the height of the diamond is irrelevant.

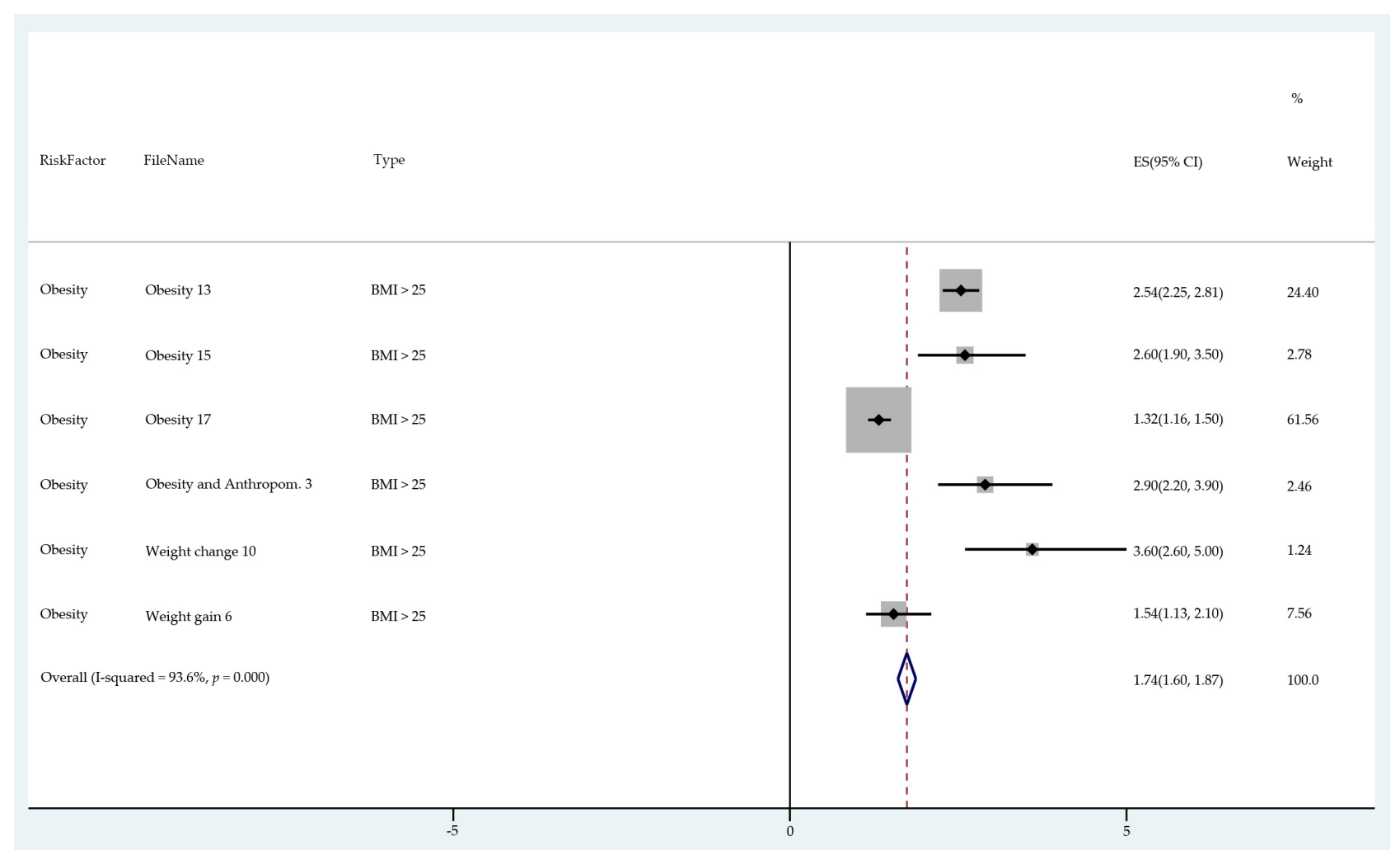

Figure 1. Forest plot to show risk of BMI $>25$.

As can be seen, different studies of certain factors yielded data in high agreement with each other, e.g., diabetes and continuous HRT. However, for some factors such as PCOS, various studies yielded a wider variation of results. This is demonstrated by the longer whiskers for the individual studies and more elongated diamonds in the forest plots for studies with less agreement.

The overall or pooled relative risk and the additional percentage risk above normal are summarized in Table 2 by risk factor and type.

Table 2. Pooled relative risk and percentage risk for each risk factor.

\begin{tabular}{cccc}
\hline Risk Factor & Type & Pooled Relative Risk & Percentage Risk \\
\hline Contraception & IUD & 0.52 & $-1.34 \%$ \\
& Oral & 0.68 & $-0.9 \%$ \\
\hline HRT & Continuous & 0.73 & $-0.75 \%$ \\
& Noncontinuous & 1.2 & $0.56 \%$ \\
\hline Parity & Nulliparity & 1.43 & $1.20 \%$ \\
& $\geq 1$ & 0.68 & $-0.9 \%$ \\
\hline PCOS & Yes & 2.5 & $4.2 \%$ \\
& No & 0 & $0 \%$ \\
\hline Diabetes & Yes & 1.55 & $1.54 \%$ \\
& No & 0 & $0 \%$ \\
\hline Obesity (BMI) & $<25$ & 0 & $0 \%$ \\
& $\geq 25$ and $<30$ & 1.74 & $2.01 \%$ \\
& $\geq 30$ and $<40$ & 2.87 & $6.9 \%$ \\
\hline & $>40$ & 3.47 & \\
\hline
\end{tabular}




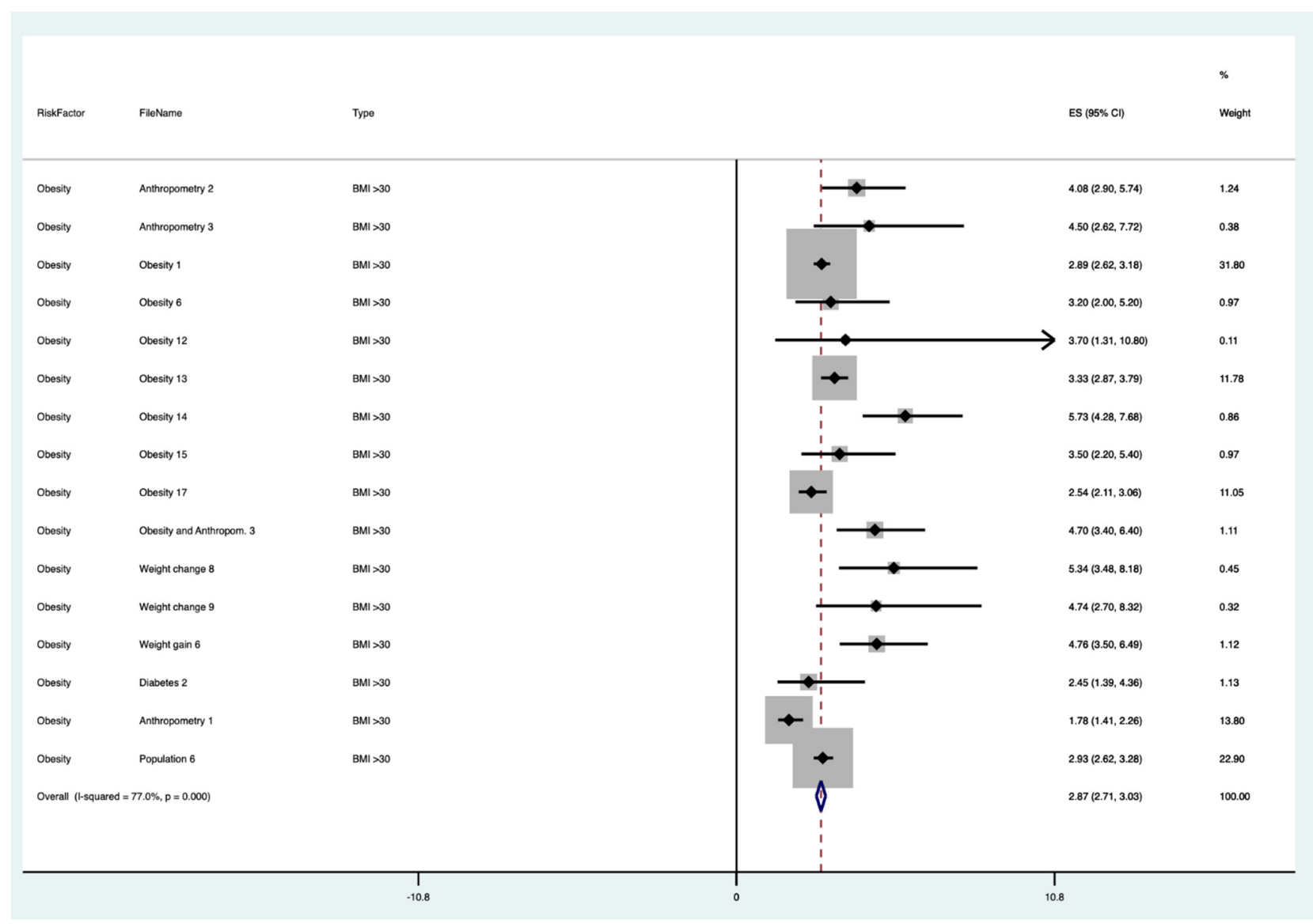

Figure 2. Forest plot to show risk of BMI $>30$.

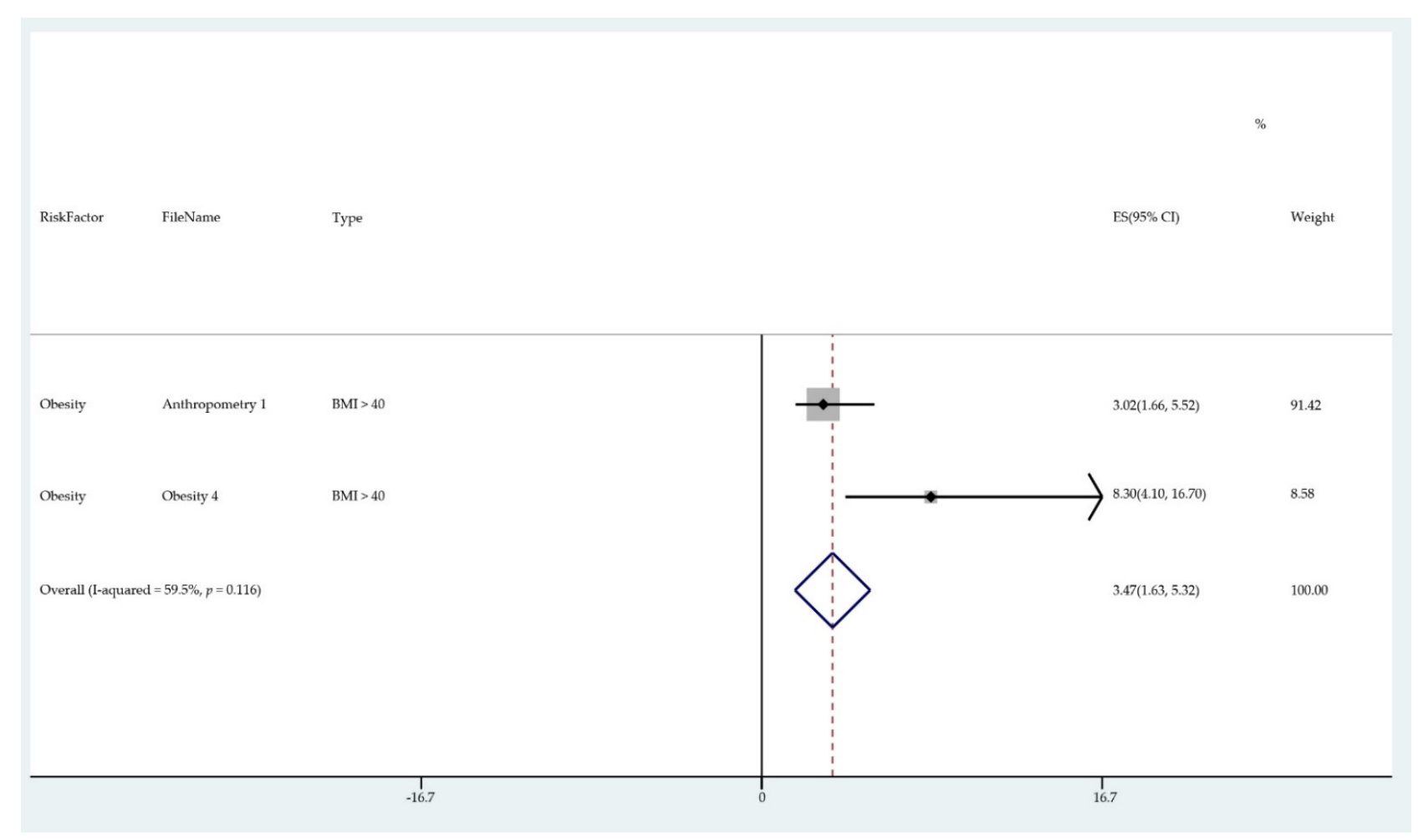

Figure 3. Forest plot to show risk of BMI $>40$. 


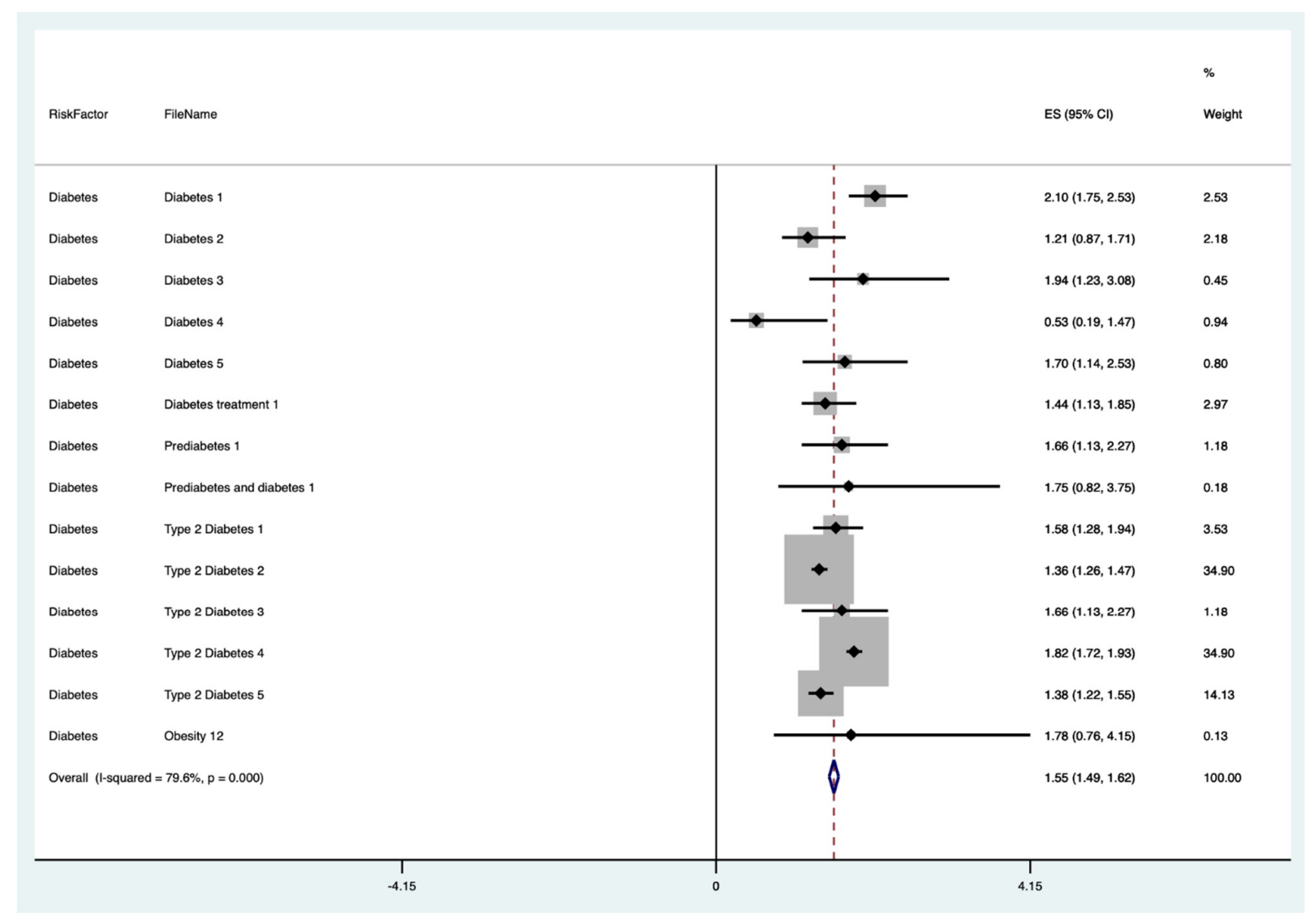

Figure 4. Forest plot to show risk of diabetes.

RiskFactor FileName Typ

ES $(95 \%$ CI $\quad$ Weight

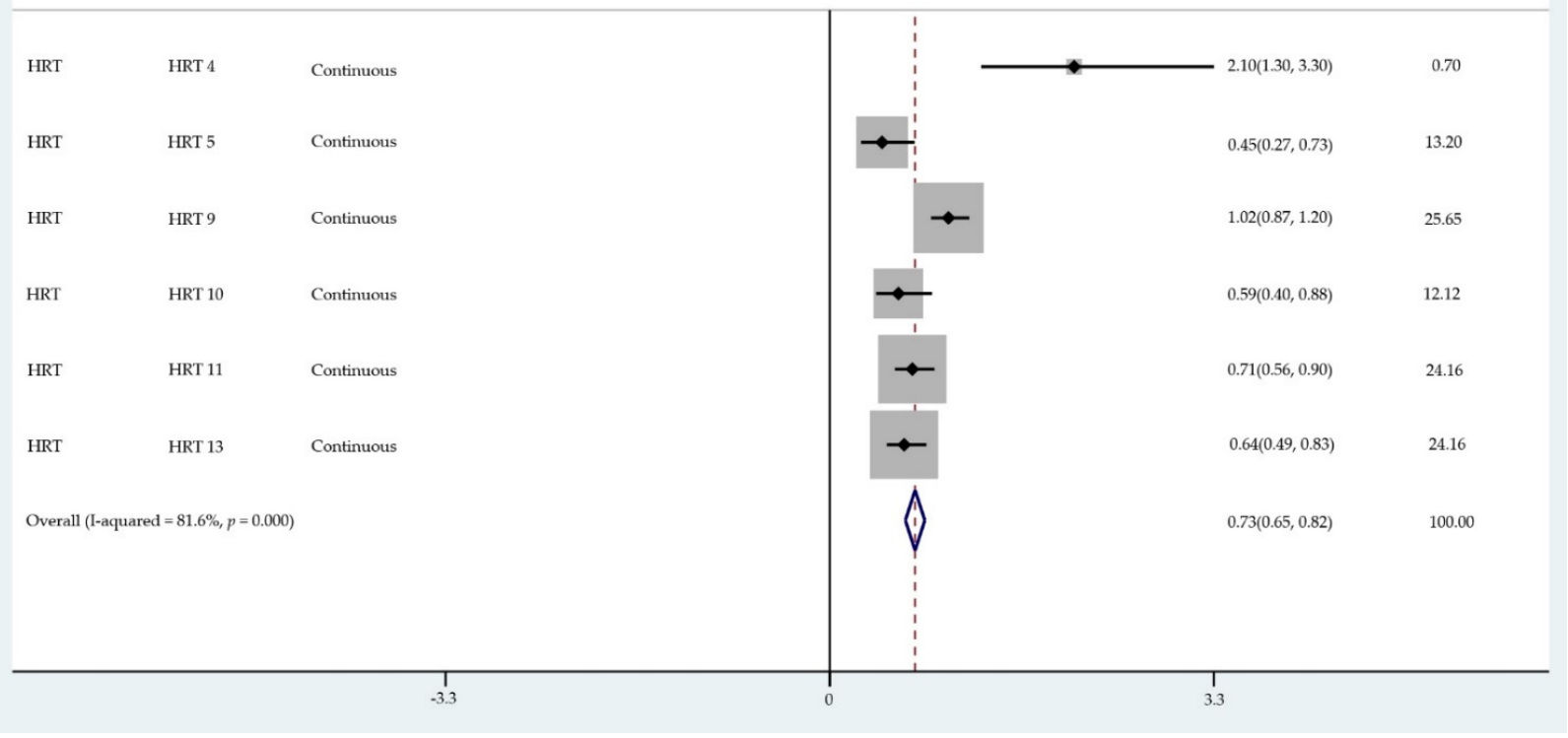

Figure 5. Forest plot to show risk of continuous HRT. 


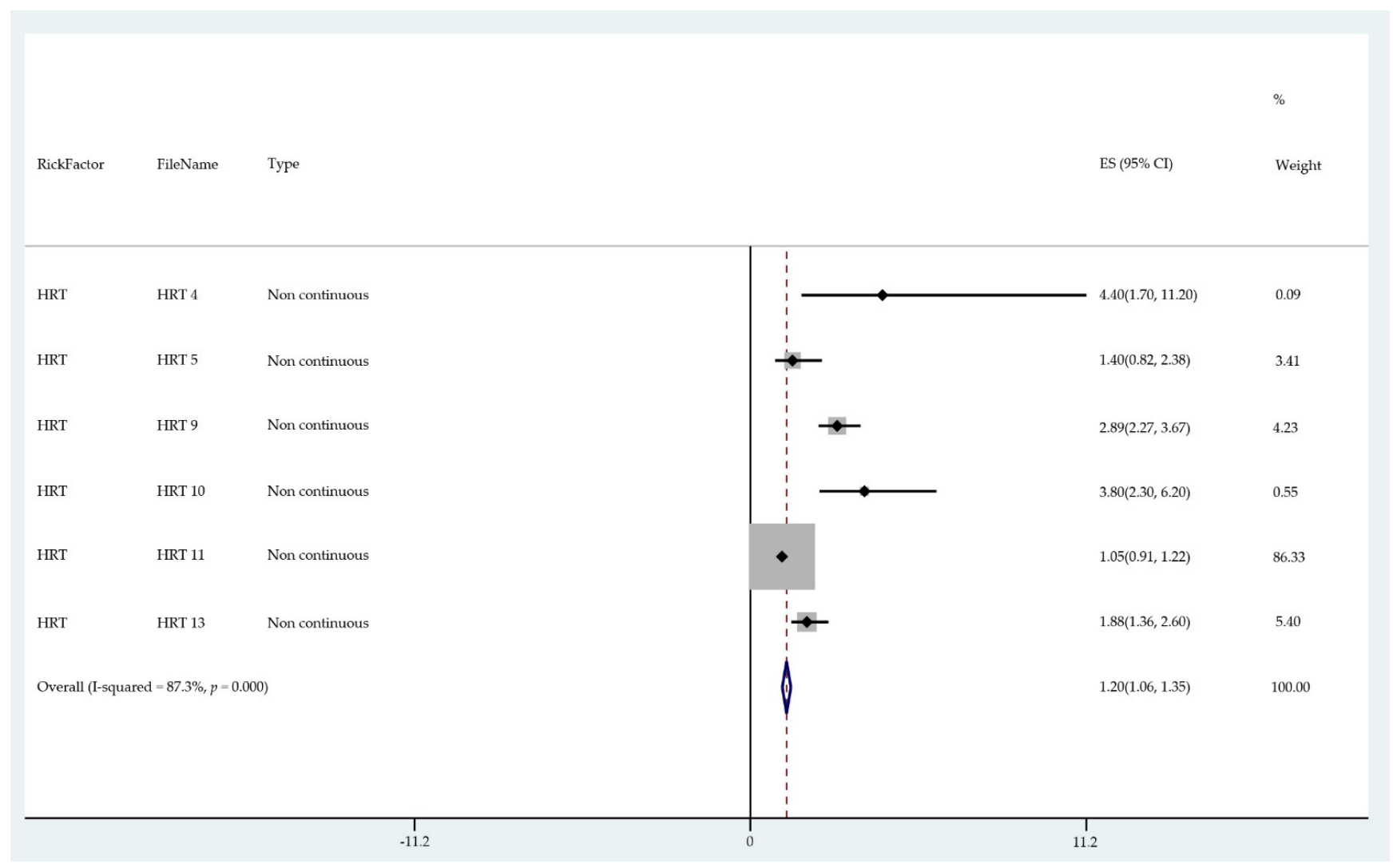

Figure 6. Forest plot to show risk of noncontinuous HRT.

\begin{tabular}{|c|c|c|c|c|c|}
\hline RiskFactor & FileName & Type & & ES $(95 \%$ CI) & Weight \\
\hline Contraception & $\mathrm{COCP}+\mathrm{IUD}$ & IUD & & $0.53(0.43,0.65)$ & 22.27 \\
\hline Contraception & IUD 1 & IUD & & $0.69(0.58,0.82)$ & 18.71 \\
\hline Contraception & IUD 2 & IUD & & $0.54(0.47,0.63)$ & 42.10 \\
\hline Contraception & MIRENA & IUD & $\rightarrow$ & $0.22(0.13,0.40)$ & 14.78 \\
\hline Contraception & HRT 5 & IUD & & $-0.39(0.17,0.88)$ & 2.14 \\
\hline Overall (I-squar & $4 \%, p=0.000)$ & & & $0.52(0.46,0.57)$ & 100.00 \\
\hline
\end{tabular}

Figure 7. Forest plot to show risk of contraception (IUD). 


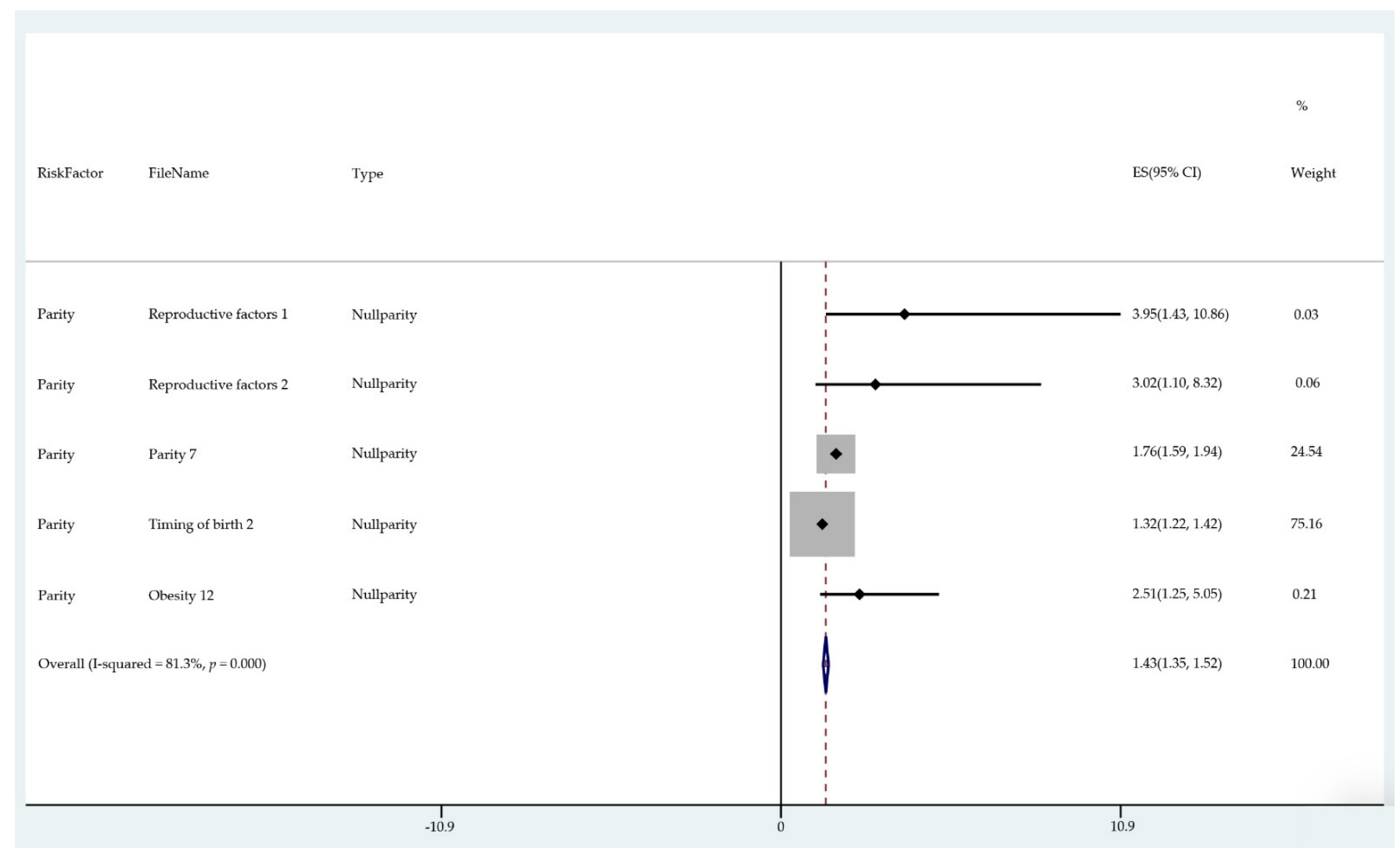

Figure 8. Forest plot to show risk of reproductive factors/null parity.

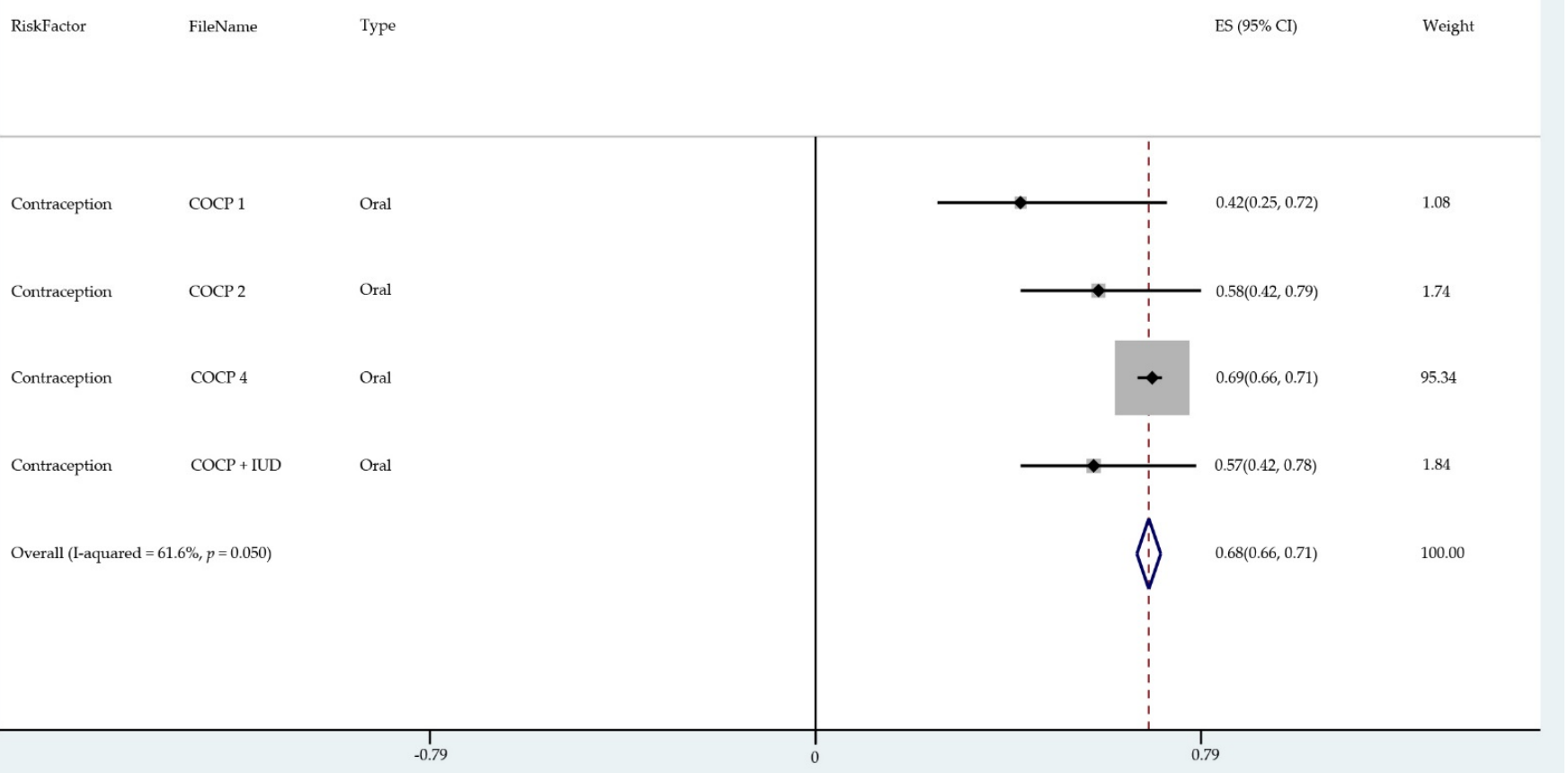

Figure 9. Forest plot to show risk of contraception (oral). 


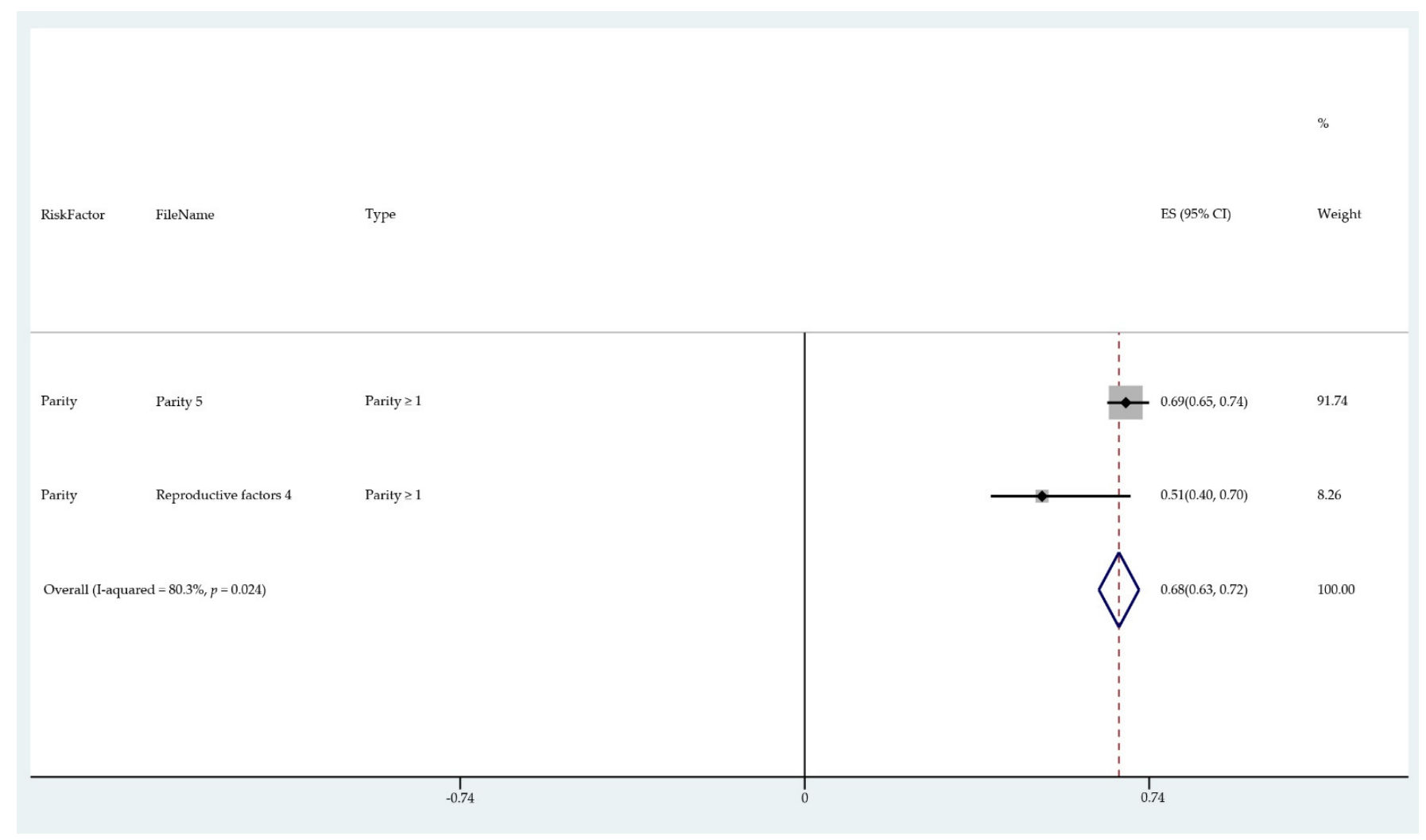

Figure 10. Forest plot to show risk of parity.

RiskFactor FileName Type

ES $(95 \%$ CI)

Weight

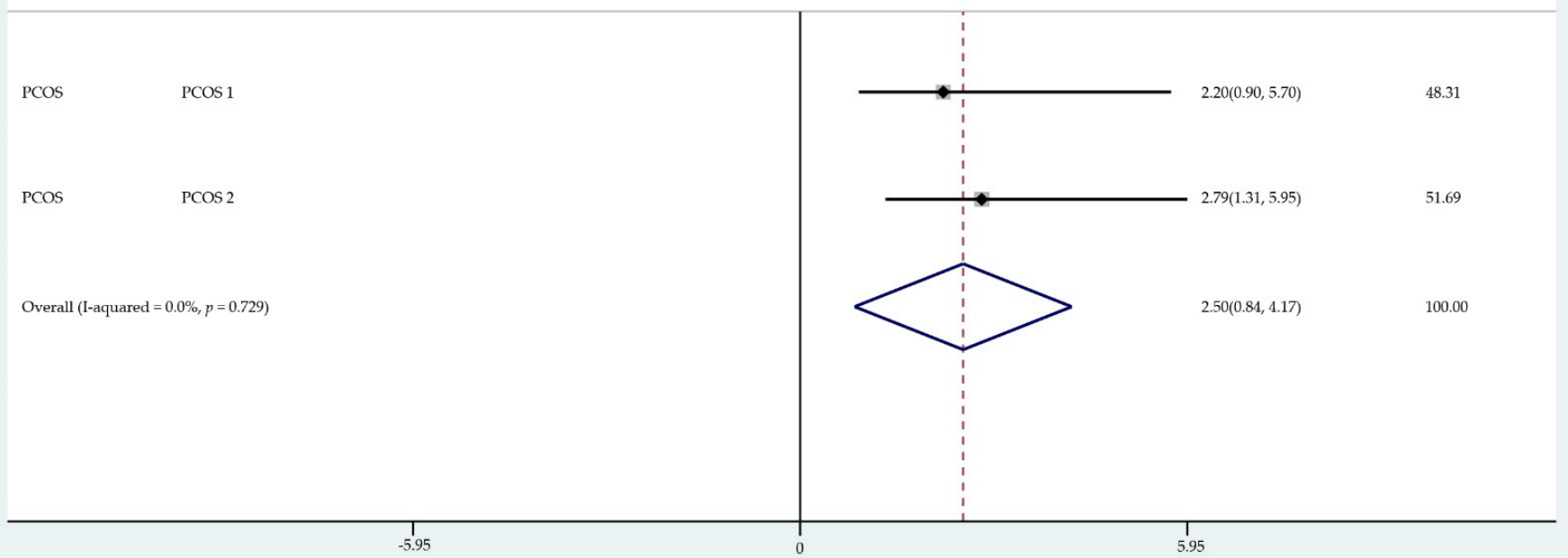

Figure 11. Forest plot to show risk of PCOS. 
The forest plots allowed an overall relative risk and percentage risk to be calculated from all the risk data from the studies. The results show that the greatest percentage of increased risk is due to BMI being above 25 , with the risk increasing as BMI increases. A BMI of 25 or over gives an increased risk of $2.01 \%$, a BMI of 30 or over gives an increase of $5.24 \%$, and a BMI of 40 or over gives an increase of $6.9 \%$. PCOS was the second highest source of increased risk at $4.2 \%$. Diabetes, which is incidentally also linked to an increased BMI, gave a significant increased risk along with nulliparity and noncontinuous HRT of $1.54 \%, 1.2 \%$, and $0.56 \%$. Decreased risk due to contraception is greatest with IUD at $-1.34 \%$ compared to $-0.9 \%$ with oral. Continuous HRT at $-0.75 \%$ and parity at $-0.9 \%$ also decrease the risk.

\subsection{Training the Software Model to Correlate Percentage Risk with Diagnosis}

To train the software the data for each factor for a given patient from the NCI database, the training set is entered into the software to model the risk. The training set established, by machine learning, the percentage risk boundary between a positive and negative diagnosis. A box plot was used to show the percentage risk output from the model, showing that those with a positive diagnosis have a significantly higher modeled risk than those with a negative diagnosis Figure 12).

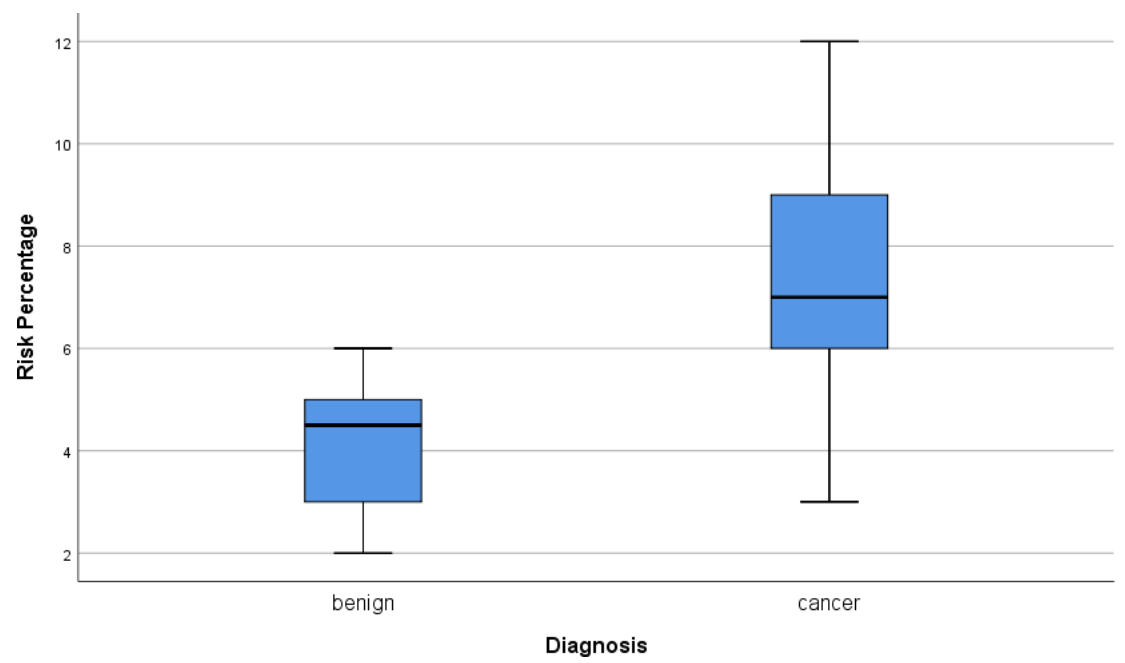

Figure 12. Diagnosis-risk percentage box plot.

Patients who eventually developed endometrial cancer had a median risk percentage of $6.9 \%$ with a maximum of $12 \%$. On the other hand, patients who did not develop endometrial cancer had a median risk percentage of $4.5 \%$, with one outlier at $6 \%$, which was considered to be in the "medium" risk category. The mean percentage risk of those with a benign diagnosis was around $4 \%$, whereas, for those patients with a positive diagnosis of endometrial cancer, the mean was $7 \%$. The software was trained to classify patients into these two categories using the overall percentage risk when given data of all the different risk factors. Thus, we demonstrated that our "percentage risk" algorithm can distinguish patients with a cancer diagnosis from those with a negative diagnosis when using the risk values for each factor derived from meta-analysis data.

\subsection{Evaluation of the Model's Ability to Correctly Predict Diagnosis}

In order to evaluate its performance, a confusion matrix was built, and several statistical measures were implemented in order to determine the level of confidence.

$>$ table(actual, prediction)

\begin{tabular}{cccc} 
& & \multicolumn{2}{c}{ prediction } \\
& & 0 & 1 \\
actual & 0 & 349 & 3 \\
1 & 2 & 9
\end{tabular}


The accuracy of the algorithm was determined by calculating the ratio of number of correct predictions to the total number of predictions made, i.e., Equation (1).

accuracy $=$ number of correct predictions $/$ total number of predictions

Using the NCI data testing set, our results showed that the model is $98.6 \%$ accurate. This is by any means considered to be a very good accuracy value for any machine learning algorithm. Since only $5 \%$ of the individuals in the test dataset had a cancer diagnosis, the accuracy measurement of the algorithm does not show how well this model can correctly predict those who have endometrial cancer, as it could achieve a correct result by chance given the high number of individuals in the dataset with a negative diagnosis. We, therefore, decided to calculate the specificity, which is a measure of the true negative rate, corresponding to the proportion of negative individuals that were correctly predicted as negative (specificity $=$ number of correct negative predictions $/$ total number of negative predictions); the result was an average of $98.78 \%$ when a series of different randomly picked data were entered, which again is an excellent result.

To determine how well the algorithm could correctly predict a patient with a positive diagnosis of endometrial cancer, we calculated the sensitivity of the algorithm; the result was an average of $75 \%$ according to several runs of the algorithm (sensitivity = number of correct positive predictions/total number of positive predictions). The lower percentage was probably due to only $5 \%$ of the data having a positive diagnosis, which may not be enough for the model to be trained well enough to predict more precisely.

Considering that BMI was the biggest contributor to the modeled percentage risk, we wanted to determine the relationship between BMI alone and the modeled percentage risk calculated using all the factors of individual patients, to determine the strength of the relationship. We did this using data from a further 40 patients currently suspected of having endometrial cancer and undergoing investigations and treatment at Royal Surrey Hospital. There was a strong positive correlation between the modeled percentage risk and BMI. This is shown in a scatter plot of the risk percentage of the patients and their BMI by diagnosis (Figure 13). The plot also shows that a cancer diagnosis also positively correlated with BMI and risk percentage, as shown by the red points being clustered more to the upper part of the $x$ - and $y$-axes, corresponding to a higher BMI/ risk percentage. From the plot, a BMI of $>25$ was associated with a cancer diagnosis with the exception of one patient. Furthermore, it could also be deduced that a negative diagnosis only correlated with a risk percentage of $5 \%$ or less, and most cancer diagnoses had a risk percentage of $6 \%$ or more. This further shows that our modeled risk percentage correlated well with diagnosis.

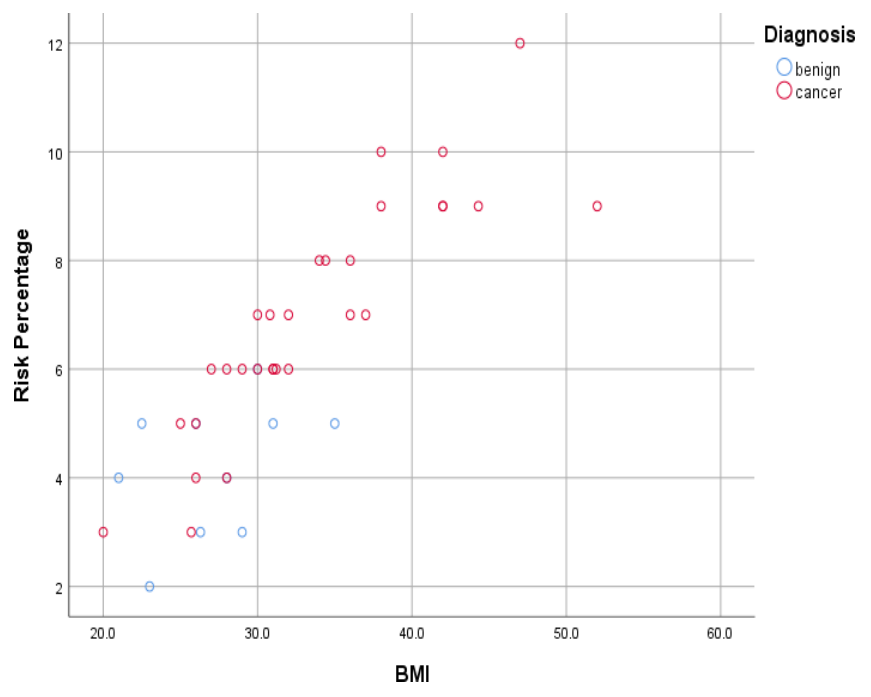

Figure 13. BMI-risk percentage scatter plot. 


\section{Conclusions}

In this study, we successfully determined the rank order of risk factors for endometrial cancer and calculated a pooled risk and risk percentage for each factor using a statistical meta-analysis approach. Then, using a computer neural network model system, we were able to model the overall increase or decreased risk of cancer and predict the cancer diagnosis for particular patients to an accuracy of over $98 \%$.

The analysis of the risk factors determined that by far the biggest risk factor is obesity with a marked increased risk as BMI increases. Obesity has been linked to many cancers and is currently recognized as the single biggest risk factor [73]. In the case of endometrial cancer, as with other cancers, there is growing evidence that obesity increases the levels of estrogen, which is a proven cell proliferation and cell turnover agent, particularly for cells with endothelial origin. Indeed, epidemiological studies have confirmed an increased risk of endometrial cancer in women with high estrogen levels [74]. Estrogen induces this endometrial proliferation through the local production of IGF-1 [75]. This rapid cell division increases the risk of genetic mutations in proto-oncogenes and tumor suppressor genes, in addition to increasing free-radical-mediated DNA damage and inhibiting apoptosis [75,76]. This, in the presence of deceased levels of progesterone (as seen in postmenopausal women when the ovaries no longer produce progesterone, but instead testosterone, or in women with PCOS), leads to the "unopposed estrogen theory", where estrogen is not counterbalanced by the protective effects of progesterone.

Obesity leads to high levels of estrogen, as adipose tissue can convert androstenedione and testosterone into estrogen and estradiol using aromatase and $17 \beta$-hydroxysteroid dehydrogenase (17 $\beta-H S D)[77,78]$; thus, estrogen production is enhanced in obese individuals.

If this increased production is not accompanied by progesterone, as is the case in postmenopausal women or women with PCOS, the risks of cancer are shown to be higher. This is due to progesterone counteracting the mitogenic effects of estrogen by raising levels of IGF- binding protein-1 (IGFPB-1), which binds excess IGF-1. This in turn increases expression of the estrogen sulfotransferase and 17 $\beta$-HSD enzymes, which transform estradiol into more benign estrone [75]. This would explain why women with PCOS, who do not have the protective effects of progesterone during the luteal phase of the menstrual cycle, are at an increased risk of endometrial cancer. In contrast, users of progesterone-releasing IUDs have a significantly lower risk of endometrial cancer than nonusers [79]. Furthermore, the use of the combined oral contraceptive pill (COCP) for $\geq 5$ years is associated with a significant reduction in endometrial cancer risk due to suppression of endogenous estrogen levels and increased exposure to progesterone throughout the menstrual cycle [9]. For the same reason, increasing parity is also a protective factor [22].

Obese women have higher insulin levels than their normal-weight counterparts; excess fat tissue reduces the responsiveness of the body to the effects of insulin; hence, levels increase to compensate. Endometrial cell proliferation is also stimulated by insulin. There is evidence for a direct effect on endometrial cancer cells of insulin and IGF-1; activation of the insulin receptor causes an increase in cell proliferation and inhibition of apoptosis $[76,80,81]$ through both the MAPK and PI3K/Akt pathways. Insulin and IGF-1 also stimulate $\beta$-catenin, a signaling pathway involved in early tumor formation, and the Ras oncogene. Insulin increases the breakdown of IGFBP-3, thus increasing the levels of free IGF-1, promoting tumor formation. Interestingly, elevated serum insulin levels have been shown to be present in women with endometrial cancer, compared with those without the disease [74].

Obesity is characterized by chronic inflammation [82], with fat tissue producing inflammatory and carcinogenic (cancer promoting) proteins through the release of adipokines, cytokines, and sex hormone metabolism [83]; hence, obese women have elevated levels compared with normal-weight women [74]. Cytokines are produced by the activated adipocytes and infiltrating macrophages in response to expansion of the adipose tissue and localized hypoxia. Increasing BMI is associated with elevated levels of cytokines including IFNs, IL6, IL8, IL1 receptor antagonist (IL-1Ra), and C-reactive peptide (CRP) [76,84,85]. 
Chronic inflammation results in the generation of free radicals, as well as increased concentrations of COX2 and prostaglandin E2, leading to cell proliferation and DNA damage [86]. In addition, activation of the NF- $\mathrm{KB}$ pathway by inflammatory cytokines inhibits apoptosis, overcoming cell-cycle arrest, and leads to the transcription of genes encoding proinflammatory cytokines. This cycle of inflammation can result in tumor formation. Inflammation can also cause insulin resistance, and IL6 can stimulate aromatase activity and the conversion of androgens into estrogen within adipose tissue, which all contribute to the ideal conditions for tumor formation [85].

The neural network model developed in this study was shown to be a potentially useful tool in determining the percentage risk and predicting the possibility of a given patient developing endometrial cancer. The risk factors analyzed are not linked to specific histological types or the new molecular classification [87]. As such, this could be a useful tool for clinicians to use in conjunction with other biomarkers in determining which patients warrant further preventative interventions progressing to endometrial cancer. This result would allow for a reduction in the number of unnecessary invasive classical tests on patients. The model may also be used to suggest interventions to decrease the risk for a particular patient. The sensitivity of the model limits it at this stage due to the small percentage of positive cases in the datasets; however, since this model utilizes a neural network machine learning algorithm, it can be further improved by providing the system with more and larger datasets to allow further refinement of the neural network.

Supplementary Materials: The following are available online at https://www.mdpi.com/article/10 .3390/cancers13153689/s1: File S1: R-script file.

Author Contributions: Conceptualization, A.M.P.; data curation, S.H. and A.M.P.; formal analysis, S.H., D.M., and A.M.P.; funding acquisition, J.C.; investigation, S.H., A.M.P., and J.C.; methodology, A.M.P.; project administration, S.H., E.K., A.M., A.M.P., and J.C.; resources, A.M.P.; software, D.M. and A.M.P.; supervision, A.M., A.M.P., and J.C.; writing—original draft, A.M.P.; writing—review and editing, E.K., A.M., A.M.P., and J.C. All authors read and agreed to the published version of the manuscript.

Funding: This research received no external funding.

Institutional Review Board Statement: The study was conducted according to the guidelines of the Declaration of Helsinki and approved by the Ethics Committees of Royal Surrey NHS Foundation Trust Hospital and Brunel University London.

Informed Consent Statement: Informed consent was obtained from all subjects involved in the study.

Data Availability Statement: The data used in the study are publicly available in the references cited within the text or are available on request from the corresponding author.

Acknowledgments: We gratefully acknowledge the support of staff and the use of facilities at the Department of Gynecological Oncology, Royal Surrey NHS Foundation Trust Hospital, Department of Clinical and Experimental Medicine, School Biosciences and Medicine, Faculty of Health and Medical Sciences, University of Surrey, Department of Computer Science, College of Engineering, Design, and Physical Sciences, Brunel University, Department of Life Sciences, Division of Biosciences, College of Health, Medicine, and Life Sciences, Brunel University, and Department Cancer and Surgery, Imperial College London.

Conflicts of Interest: The authors declare no conflict of interest.

\section{References}

1. Cancer Research UK. Uterine (Womb) Cancer Incidence Statistics. Cancer Stats: Cancer Statistics for the UK. Available online: https:/ / www.cancerresearchuk.org/health-professional/cancer-statistics/statistics-by-cancer-type/uterine-cancer/incidence?_gl=1*d8jajt*ga*MTE0NTI5NTI2MC4xNjI0NTIzODU2*_ga_58736Z2GNN*MTYyNDUyMzg1NS4xLjEuMTYyNDUyMzg5 Ni4xOQ.\&_ga=2.84376858.2070757805.1624523856-1145295260.1624523856 (accessed on 24 June 2021).

2. Sonoda, Y.; Barakat, R.R. Screening and the prevention of gynecologic cancer: Endometrial cancer. Best Pract. Res. Clin. Obstet. Gynaecol. 2006, 20, 363-377. [CrossRef] [PubMed] 
3. Pecorelli, S.; Pasinetti, B.; Angioli, R.; Favalli, G.; Odicino, F. Systemic therapy for gynecological neo-plasms: Ovary, cervix, and endometrium. Cancer Chemother. Biol. Response Modif. 2005, 22, 515.

4. Kitson, S.J.; Evans, D.G.; Crosbie, E.J. Identifying high-risk women for endometrial cancer prevention strategies: Proposal of an endometrial cancer risk prediction model. Cancer Prev. Res. 2017, 10, 1-13. [CrossRef]

5. $\quad$ Reeves, G.K.; Pirie, K.; Beral, V.; Green, J.; Spencer, E.; Bull, D. Cancer incidence and mortality in relation to body mass index in the Million Women Study: Cohort study. BMJ 2007, 335, 1134. [CrossRef]

6. Renehan, A.G.; Tyson, M.; Egger, M.; Heller, R.F.; Zwahlen, M. Body-mass index and incidence of cancer: A systematic review and me-ta-analysis of prospective observational studies. Lancet 2008, 371, 569-578. [CrossRef]

7. Zhou, B.; Yang, L.; Sun, Q.; Cong, R.; Gu, H.; Tang, N.; Wang, B. Cigarette smoking and the risk of endometrial cancer: A meta-analysis. Am. J. Med. 2008, 121, 501-508. [CrossRef] [PubMed]

8. American Cancer Society. Endometrial Cancer Causes, Risk Factors, and Prevention. Available online: https://www.cancer.org/ content/dam/CRC/PDF/Public/8610.00.pdf (accessed on 15 April 2021).

9. Dossus, L.; Allen, N.; Kaaks, R.; Bakken, K.; Lund, E.; Tjonneland, A.; Olsen, A.; Overvad, K.; Clavel-Chapelon, F.; Fournier, A.; et al. Reproductive risk factors and endometrial cancer: The European Prospective Investigation into Cancer and Nutrition. Int. J. Cancer 2010, 127, 442-451. [CrossRef]

10. Hardiman, P.; Pillay, O.S.; Atiomo, W. Polycystic ovary syndrome and endometrial carcinoma. Lancet 2003, 361, 1810-1812. [CrossRef]

11. Sjögren, L.L.; Mørch, L.S.; Løkkegaard, E. Hormone replacement therapy and the risk of endometrial cancer: A systematic review. Maturitas 2016, 91, 25-35. [CrossRef]

12. Cancer Research UK: Uterine Cancer Statistics. Available online: https://www.cancerresearchuk.org/health-professional/cancerstatistics / statisticsby-cancer-type/uterine-cancer\#heading-Zero (accessed on 15 April 2021).

13. Filomeno, M.; Bosetti, C.; Bidoli, E.; Levi, F.; Serraino, D.; Montella, M.; La Vecchia, C.; Tavani, A. Mediterranean diet and risk of endometrial cancer: A pooled analysis of three italian case-control studies. Br. J. Cancer 2015, 112, 1816-1821. [CrossRef]

14. Sikarin, U.; Sanguankeo, A. Bariatric surgery and risk of postoperative endometrial cancer: A systematic re-view and metaanalysis. Surg. Obes. Relat. Dis. 2015, 11, 949-955.

15. Tseng, C.-H. Metformin and endometrial cancer risk in Chinese women with type 2 diabetes mellitus in Taiwan. Gynecol. Oncol. 2015, 138, 147-153. [CrossRef] [PubMed]

16. Meireles, C.G.; Pereira, S.A.; Valadares, L.P.; Rego, D.F.; Simeoni, L.A.; Guerra, E.N.S.; Lofrani-Porto, A. Effects of metformin on endometrial cancer: Systematic review and meta-analysis. Gynecol. Oncol. 2017, 147, 167. [CrossRef]

17. Cruz, J.A.; Wishart, D.S. Applications of Machine Learning in Cancer Prediction and Prognosis. Cancer Inform. 2006, 2, 59-77. [CrossRef]

18. Islam, M.M.; Poly, T.A. Machine Learning Models of Breast Cancer Risk Prediction. bioRxiv 2019. [CrossRef]

19. Banks, E. Endometrial cancer and hormone-replacement therapy in the Million Women Study. Lancet 2005, 365, $1543-1551$. [CrossRef]

20. Gierisch, J.M.; Coeytau, R.R.; Urrutia, R.P.; Havirilesky, L.J.; Moorman, P.G.; Lowery, W.J.; Dinan, M.; McBroom, A.J.; Hasselblad, V.; Sanders, G.D.; et al. Oral ContraceptiveUse and Risk of Breast, Cervical, Colo-rectal, and Endometrial Cancers: A Systematic Review. Cancer Epidemiol. Biomark. Prev. 2013, 22, 1931-1943. Available online: https://cebp.aacrjournals.org/content/22/11/19 31 (accessed on 13 July 2021). [CrossRef] [PubMed]

21. Gambacciani, M.; Monteleone, P.; Sacco, A.; Genazzani, A. Hormone replacement therapy and endometrial, ovarian and colorectal cancer. Best Pr. Res. Clin. Endocrinol. Metab. 2003, 17, 139-147. [CrossRef]

22. Wu, Q.-J.; Li, Y.-Y.; Tu, C.; Zhu, J.; Qian, K.-Q.; Feng, T.-B.; Li, C.; Wu, L.; Ma, X.-X. Parity and endometrial cancer risk: A meta-analysis of epidemiological studies. Sci. Rep. 2015, 5, 14243. [CrossRef]

23. Schonfeld, S.J.; Hartge, P.; Pfeiffer, R.M.; Freedman, D.M.; Greenlee, R.T.; Linet, M.S.; Park, Y.; Schairer, C.; Visvanathan, K.; Lacey, J.V. An aggregated analysis of hormonal factors and endometrial cancer risk by parity. Cancer 2013, 119, 1393-1401. [CrossRef] [PubMed]

24. Jenabi, E.; Poorolajal, J. The effect of body mass index on endometrial cancer: A meta-analysis. Public Health 2015, 129, 872-880. [CrossRef]

25. Gao, Y.; Dai, X.; Chen, L.; Lee, A.; Tong, M.; Wise, M.; Chen, Q. Body Mass Index Is Positively Associated with Endometrial Cancer in Chinese Women, Especially Prior to Menopause. J. Cancer 2016, 7, 1169-1173. [CrossRef] [PubMed]

26. Zhang, Y.; Liu, H.; Yang, S.; Zhang, J.; Qian, L.; Chen, X. Overweight, Obesity and Endometrial Cancer Risk: Results from a Systematic Review and Meta-Analysis. Int. J. Biol. Markers 2014, 29, e21-e29. [CrossRef] [PubMed]

27. Xu, W.H.; Matthews, C.E.; Xiang, Y.B.; Zheng, W.; Ruan, Z.X.; Cheng, J.R.; Gao, Y.T.; Shu, X.O. Effect of Adiposity and Fat Distribution on Endometrial Cancer Risk in Shanghai Women. Am. J. Epidemiol. 2005, 161, 939-947. [CrossRef]

28. Nagle, C.; Marquart, L.; Bain, C.; O’Brien, S.; Lahmann, P.; Quinn, M.; Oehler, M.; Obermair, A.; Spurdle, A.; Webb, P. Impact of weight change and weight cycling on risk of different subtypes of endometrial cancer. Eur. J. Cancer 2013, 49, 2717-2726. [CrossRef]

29. Lu, L.; Risch, H.; Irwin, M.L.; Mayne, S.T.; Cartmel, B.; Schwartz, P.; Rutherford, T.; Yu, H. Long-term overweight and weight gain in early adulthood in association with risk of endometrial cancer. Int. J. Cancer 2011, 129, 1237-1243. [CrossRef] 
30. Maso, L.D.; Tavani, A.; Zucchetto, A.; Montella, M.; Ferraroni, M.; Negri, E.; Polesel, J.; Decarli, A.; Talamini, R.; La Vecchia, C.; et al. Anthropometric measures at different ages and endometrial cancer risk. Br. J. Cancer 2011, 104, 1207-1213. [CrossRef] [PubMed]

31. Schouten, L.J.; Goldbohm, R.A.; Brandt, P.V.D. Anthropometry, Physical Activity, and Endometrial Cancer Risk: Results from The Netherlands Cohort Study. J. Natl. Cancer Inst. 2004, 96, 1635-1638. [CrossRef]

32. Jonsson, F.; Wolk, A.; Pedersen, N.L.; Lichtenstein, P.; Terry, P.; Ahlbom, A.; Feychting, M. Obesity and hormone-dependent tumors: Cohort and co-twin control studies based on the Swedish Twin Registry. Int. J. Cancer 2003, 106, 594-599. [CrossRef]

33. Wise, M.R.; Gill, P.; Lensen, S.; Thompson, J.M.; Farquhar, C. Body mass index trumps age in decision for endometrial biopsy: Cohort study of symptomatic premenopausal women. Am. J. Obstet. Gynecol. 2016, 215, 598.e1-598.e8. [CrossRef]

34. Rota, M.; Rumi, F.; Bagnardi, V.; Maso, L.D.; Zucchetto, A.; Levi, F.; La Vecchia, C.; Tavani, A. Modelling body mass index and endometrial cancer risk in a pooled-analysis of three case-control studies. BJOG Int. J. Obstet. Gynaecol. 2016, 123, $285-292$. [CrossRef]

35. Liu, Y.; Andersen, S.W.; Wen, W.; Gao, Y.-T.; Lan, Q.; Rothman, N.; Ji, B.-T.; Yang, G.; Xiang, Y.-B.; Shu, X.-O.; et al. Prospective cohort study of general and central obesity, weight change trajectory and risk of major cancers among Chinese women. Int. J. Cancer 2016, 139, 1461-1470. [CrossRef]

36. Horn-Ross, P.L.; Canchola, A.J.; Bernstein, L.; Deapen, D.; Lacey, J.V.; Lee, E.; Nelson, D.O.; Reynolds, P. Body size over the life-course and the risk of endometrial cancer: The California Teachers Study. Cancer Causes Control. 2016, 27, 1419-1428. [CrossRef]

37. Attner, B.; Landin-Olsson, M.; Lithman, T.; Noreen, D.; Olsson, H. Cancer among patients with diabetes, obesity and abnormal blood lipids: A population-based register study in Sweden. Cancer Causes Control. 2012, 23, 769-777. [CrossRef]

38. Friedenreich, C.; Cust, A.; Lahmann, P.; Steindorf, K.; Boutron-Ruault, M.-C.; Clavel-Chapelon, F.; Mesrine, S.; Linseisen, J.; Rohrmann, S.; Boeing, H.; et al. Anthropometric factors and risk of endometrial cancer: The European prospective investigation into cancer and nutrition. Cancer Causes Control. 2007, 18, 399-413. [CrossRef] [PubMed]

39. Yang, H.P.; Wentzensen, N.; Trabert, B.; Gierach, G.L.; Felix, A.S.; Gunter, M.J.; Hollenbeck, A.; Park, Y.; Sherman, M.E.; Brinton, L.A. Endometrial Cancer Risk Factors by 2 Main Histologic Subtypes. Am. J. Epidemiol. 2012, 177, 142-151. [CrossRef]

40. Lindemann, K.; Vatten, L.J.; Ellstrøm-Engh, M.; Eskild, A. The impact of BMI on subgroups of uterine cancer. Br. J. Cancer 2009, 101, 534-536. [CrossRef] [PubMed]

41. Friberg, E.; Orsini, N.; Mantzoros, C.S.; Wolk, A. Diabetes mellitus and risk of endometrial cancer: A meta-analysis. Diabetologia 2007, 50, 1365-1374. [CrossRef]

42. Friberg, E.; Mantzoros, C.S.; Wolk, A. Diabetes and Risk of Endometrial Cancer: A Population-Based Prospective Cohort Study. Cancer Epidemiol. Biomark. Prev. 2007, 16, 276-280. [CrossRef] [PubMed]

43. Lindemann, K.; Vatten, L.J.; Ellstrøm-Engh, M.; Eskild, A. Body mass, diabetes and smoking, and endometrial cancer risk: A follow-up study. Br. J. Cancer 2008, 98, 1582-1585. [CrossRef] [PubMed]

44. Bosetti, C.; Rosato, V.; Polesel, J.; Levi, F.; Talamini, R.; Montella, M.; Negri, E.; Tavani, A.; Zucchetto, A.; Franceschi, S.; et al. Diabetes Mellitus and Cancer Risk in a Network of Case-Control Studies. Nutr. Cancer 2012, 64, 643-651. [CrossRef] [PubMed]

45. Luo, J.; Beresford, S.; Chen, C.; Chlebowski, R.; Garcia, L.; Kuller, L.; Regier, M.; Wactawski-Wende, J.; Margolis, K. Association between diabetes, diabetes treatment and risk of developing endometrial cancer. Br. J. Cancer 2014, 111, 1432-1439. [CrossRef]

46. Huang, Y.; Cai, X.; Qiu, M.; Chen, P.; Tang, H.; Hu, Y.; Huang, Y. Prediabetes and the risk of cancer: A meta-analysis. Diabetologia 2014, 57, 2261-2269. [CrossRef]

47. Lambe, M.; Wigertz, A.; Garmo, H.; Walldius, G.; Jungner, I.; Hammar, N. Impaired glucose metabolism and diabetes and the risk of breast, endometrial, and ovarian cancer. Cancer Causes Control. 2011, 22, 1163-1171. [CrossRef]

48. Johnson, J.A.; Bowker, S.L.; Richardson, K.; Marra, C.A. Time-varying incidence of cancer after the onset of type 2 diabetes: Evidence of potential detection bias. Diabetologia 2011, 54, 2263-2271. [CrossRef]

49. Lin, C.-C.; Chiang, J.-H.; Li, C.-I.; Liu, C.-S.; Lin, W.-Y.; Hsieh, T.-F.; Li, T.-C. Cancer risks among patients with type 2 diabetes: A 10-year follow-up study of a nationwide population-based cohort in Taiwan. BMC Cancer 2014, 14, 381. [CrossRef] [PubMed]

50. Oberaigner, W.; Ebenbichler, C.; Oberaigner, K.; Juchum, M.; Schönherr, H.R.; Lechleitner, M. Increased cancer incidence risk in type 2 diabetes mellitus: Results from a cohort study in Tyrol/Austria. BMC Public Health 2014, 14, 1-9. [CrossRef] [PubMed]

51. Liu, X.; Hemminki, K.; Försti, A.; Sundquist, K.; Sundquist, J.; Ji, J. Cancer risk in patients with type 2 diabetes mellitus and their relatives. Int. J. Cancer 2015, 137, 903-910. [CrossRef]

52. Lo, S.-F.; Chang, S.-N.; Muo, C.-H.; Chen, S.-Y.; Liao, F.-Y.; Dee, S.-W.; Chen, P.-C.; Sung, F.-C. Modest increase in risk of specific types of cancer types in type 2 diabetes mellitus patients. Int. J. Cancer 2012, 132, 182-188. [CrossRef] [PubMed]

53. Razavi, P.; Pike, M.C.; Horn-Ross, P.L.; Templeman, C.; Bernstein, L.; Ursin, G. Long-term Postmenopausal Hormone Therapy and Endometrial Cancer. Cancer Epidemiol. Biomark. Prev. 2010, 19, 475-483. [CrossRef] [PubMed]

54. Jaakkola, S.; Lyytinen, H.K.; Dyba, T.; Ylikorkala, O.; Pukkala, E. Endometrial cancer associated with various forms of postmenopausal hormone therapy: A case control study. Int. J. Cancer 2011, 128, 1644-1651. [CrossRef]

55. Mørch, L.S.; Kjaer, S.K.; Keiding, N.; Løkkegaard, E.; Lidegaard, Ø. The influence of hormone therapies on type I and II endometrial cancer: A nationwide cohort study. Int. J. Cancer 2016, 138, 1506-1515. [CrossRef] 
56. Doherty, J.A.; Cushing-Haugen, K.L.; Saltzman, B.S.; Voigt, L.F.; Hill, D.A.; Beresford, S.A.; Chen, C.; Weiss, N.S. Long-term use of postmenopausal estrogen and progestin hormone therapies and the risk of endometrial cancer. Am. J. Obstet. Gynecol. 2007, 197, 139.e1-139.e7. [CrossRef] [PubMed]

57. Trabert, B.; Wentzensen, N.; Yang, H.P.; Sherman, M.E.; Hollenbeck, A.R.; Park, Y.; Brinton, L.A. Is estrogen plus progestin menopausal hormone therapy safe with respect to endometrial cancer risk? Int. J. Cancer 2013, 132, 417-426. [CrossRef]

58. Tao, M.H.; Xu, W.; Zheng, W.; Zhang, Z.-F.; Gao, Y.-T.; Ruan, Z.X.; Cheng, J.R.; Gao, J.; Xiang, Y.B.; Shu, X.O. Oral contraceptive and IUD use and endometrial cancer: A population-based case-control study in Shanghai, China. Int. J. Cancer 2006, 119, 2142-2147. [CrossRef]

59. Felix, A.S.; Gaudet, M.M.; La Vecchia, C.; Nagle, C.M.; Shu, X.O.; Weiderpass, E.; Adami, H.O.; Beresford, S.; Bernstein, L.; Chen, C.; et al. Intrauterine devices and endometrial cancer risk: A pooled analysis of the Epidemiology of Endometrial Cancer Consortium. Int. J. Cancer 2015, 136, E410-E422. [CrossRef]

60. Beining, R.M.; Dennis, L.K.; Smith, E.M.; Dokras, A. Meta-Analysis of Intrauterine Device Use and Risk of Endometrial Cancer. Ann. Epidemiol. 2008, 18, 492-499. [CrossRef] [PubMed]

61. Jareid, M.; Thalabard, J.-C.; Aarflot, M.; Bøvelstad, H.M.; Lund, E.; Braaten, T. Levonorgestrel-releasing intrauterine system use is associated with a decreased risk of ovarian and endometrial cancer, without increased risk of breast cancer. Results from the NOWAC Study. Gynecol. Oncol. 2018, 149, 127-132. [CrossRef]

62. Wernli, K.J.; Ray, R.M.; Gao, D.L.; De Roos, A.J.; Checkoway, H.; Thomas, D.B. Menstrual and reproductive factors in relation to risk of endometrial cancer in Chinese women. Cancer Causes Control. 2006, 17, 949-955. [CrossRef] [PubMed]

63. Xu, W.; Xiang, Y.-B.; Ruan, Z.-X.; Zheng, W.; Cheng, J.-R.; Dai, Q.; Gao, Y.-T.; Shu, X.-O. Menstrual and reproductive factors and endometrial cancer risk: Results from a population-based case-control study in urban Shanghai. Int. J. Cancer 2004, 108, 613-619. [CrossRef] [PubMed]

64. Yang, H.P.; Cook, L.S.; Weiderpass, E.; Adami, H.-O.; E Anderson, K.; Cai, H.; Cerhan, J.R.; Clendenen, T.V.; Felix, A.S.; Friedenreich, C.M.; et al. Infertility and incident endometrial cancer risk: A pooled analysis from the epidemiology of endometrial cancer consortium (E2C2). Br. J. Cancer 2015, 112, 925-933. [CrossRef]

65. Pfeiffer, R.M.; Mitani, A.; Landgren, O.; Ekbom, A.; Kristinsson, S.Y.; Björkholm, M.; Biggar, R.J.; Brinton, L.A. Timing of births and endometrial cancer risk in Swedish women. Cancer Causes Control. 2009, 20, 1441-1449. [CrossRef]

66. Cook, L.S.; Dong, Y.; Round, P.; Huang, X.; Magliocco, A.M.; Friedenreich, C.M. Hormone Contraception before the First Birth and Endometrial Cancer Risk. Cancer Epidemiol. Biomark. Prev. 2014, 23, 356-361. [CrossRef]

67. Hannaford, P.C.; Selvaraj, S.; Elliott, A.M.; Angus, V.; Iversen, L.; Lee, A.J. Cancer risk among users of oral contraceptives: Cohort data from the Royal College of General Practitioner's oral contraception study. BMJ 2007, 335, 651. [CrossRef] [PubMed]

68. Allen, N.; Peto, R.; Beral, V.; Kan, S.; Reeves, G.; Sweetland, S.; Stevens, R.; Yang, T.; Brandt, P.V.D.; The Collaborative Group on Epidemiological Studies on Endometrial Cancer; et al. Endometrial cancer and oral contraceptives: An individual participant meta-analysis of 27276 women with endometrial cancer from 36 epidemiological studies. Lancet Oncol. 2015, 16, 1061-1070. [CrossRef]

69. A Brinton, L.; Sakoda, L.C.; Lissowska, J.; E Sherman, M.; Chatterjee, N.; Peplonska, B.; Szeszenia-Dabrowska, N.; Zatonski, W.; Garcia-Closas, M. Reproductive risk factors for endometrial cancer among Polish women. Br. J. Cancer 2007, 96, 1450-1456. [CrossRef]

70. Fearnley, E.J.; Marquart, L.; Spurdle, A.B.; Weinstein, P.; Webb, P.M.; The Australian Ovarian Cancer Study Group; The Australian National Endometrial Cancer Study Group. Polycystic ovary syndrome increases the risk of endometrial cancer in women aged less than 50 years: An Australian case-control study. Cancer Causes Control. 2010, 21, 2303-2308. [CrossRef] [PubMed]

71. Barry, J.; Azizia, M.M.; Hardiman, P.J. Risk of endometrial, ovarian and breast cancer in women with polycystic ovary syndrome: A systematic review and meta-analysis. Hum. Reprod. Update 2014, 20, 748-758. [CrossRef]

72. Cancer Research UK: Lifetime Risk of Cancer. Available online: https://www.cancerresearchuk.org/health-professional/ cancerstatistics/risk/lifetime-risk\#heading-One (accessed on 15 April 2021).

73. James, W.P.T. WHO recognition of the global obesity epidemic. Int. J. Obes. 2008, 32, S120-S126. [CrossRef] [PubMed]

74. Dossus, L.; Lukanova, A.; Rinaldi, S.; Allen, N.; Cust, A.E.; Becker, S.; Tjonneland, A.; Hansen, L.; Overvad, K.; Chabbert-Buffet, N.; et al. Hormonal, Metabolic, and Inflammatory Profiles and Endometrial Cancer Risk Within the EPIC Cohort-A Factor Analysis. Am. J. Epidemiol. 2013, 177, 787-799. [CrossRef] [PubMed]

75. Kaaks, R.; Lukanova, A.; Kurzer, M.S. Obesity, endogenous hormones, and endometrial cancer risk: A synthetic review. Cancer Epidemiol. Biomark. Prev. 2002, 11, 1531-1543.

76. Renehan, A.G.; Roberts, D.; Dive, C. Obesity and cancer: Pathophysiological and biological mechanisms. Arch. Physiol. Biochem. 2008, 114, 71-83. [CrossRef] [PubMed]

77. Siiteri, P.K. Steroid hormones and endometrial cancer. Cancer Res. 1978, 38, 4360-4366.

78. Calle, E.E.; Kaaks, R. Overweight, obesity and cancer: Epidemiological evidence and proposed mechanisms. Nat. Rev. Cancer 2004, 4, 579-591. [CrossRef]

79. Soini, T.; Hurskainenm, R.; Grenmanm, S.; Maenpaam, J.; Paavonen, J.; Pukkala, E. Cancer risk in women using the levonorgestrel-releasing intrauterine system in Finland. Obstet. Gynecol. 2014, 124, 292-299. [CrossRef]

80. Renehan, A.G.; Frystyk, J.; Flyvbjerg, A. Obesity and cancer risk: The role of the insulin-IGF axis. Trends Endocrinol. Metab. 2006, 17, 328-336. [CrossRef] [PubMed] 
81. Nagamani, M.; Stuart, C.A. Specific binding and growth-promoting activity of insulin in endometrial cancer cells in culture. Am. J. Obstet. Gynecol. 1998, 179, 6-12. [CrossRef]

82. Ye, J.; Keller, J. Regulation of energy metabolism by inflammation: A feedback response in obesity and calorie restriction. Aging 2010, 2, 361-368. [CrossRef] [PubMed]

83. Schmandt, R.E.; Iglesias, D.A.; Na Co, N.; Lu, K.H. Understanding obesity and endometrial cancer risk: Opportunities for prevention. Am. J. Obstet. Gynecol. 2011, 205, 518-525. [CrossRef]

84. Linkov, F.; Maxwell, G.L.; Felix, A.S.; Lin, Y.; Lenzner, D.; Bovbjerg, D.H.; Lokshin, A.; Hennon, M.; Jakicic, J.M.; Goodpaster, B.H.; et al. Longitudinal evaluation of cancer-associated biomarkers before and after weight loss in RENEW study participants: Implications for cancer risk reduction. Gynecol. Oncol. 2012, 125, 114-119. [CrossRef]

85. Dossus, L.; Rinaldi, S.; Becker, S.; Lukanova, A.; Tjonneland, A.; Olsen, A.; Stegger, J.; Overvad, K.; Chabbert-Buffet, N.; JimenezCorona, A.; et al. Obesity, inflammatory markers, and endometrial cancer risk: A prospective case-control study. Endocr.-Relat. Cancer 2010, 17, 1007-1019. [CrossRef] [PubMed]

86. Modugno, F.; Ness, R.B.; Chen, C.; Weiss, N.S. Inflammation and Endometrial Cancer: A Hypothesis. Cancer Epidemiol. Biomark. Prev. 2005, 14, 2840-2847. [CrossRef] [PubMed]

87. Santoro, A.; Angelico, G.; Travaglino, A.; Inzani, F.; Arciuolo, D.; Valente, M.; D’Alessandris, N.; Scaglione, G.; Fiorentino, V.; Raffone, A.; et al. New Pathological and Clinical Insights in Endometrial Cancer in View of the Updated ESGO/ESTRO/ESP Guidelines. Cancers 2021, 13, 2623. [CrossRef] [PubMed] 